st Visited (3) Getting Started $\$$ Latest Headlines

witter / Home

\section{twiktery Search}

Home Profile Messages Who To Follow

¿ 8 Chris_Evelo -

edyong209 Ed Yong

Ah Valentine's day - when intelligent people the world over forget that emotions come from the brain not the heart 6 hours ago

Chris_Evelo chris Evelo

$S$ Prasaka K: doc2b differences in methylation in cervical and oral cancers promising biomarkers, but what is the cause? \#ISHG 7 hours ago

Chris_Evelo chris Evelo

\#ISHG a meeting about genetic and phenotypic diversity and yet they add sugar and milk to all coffee.

7 hours ago

\section{Chris_Evelo Chris Evelo}

Interesting presentations by youngsters at \#ISHG, but why do they all think a 15 min limit means you should speak faster, not say less? 7 hours ago 3 Favorite h Reply ï Delete

utopiadocs Utopia Documents

Researchers: what area would you like to use \#utopiadocs for? \#drll 7 hours ago

\section{abhishektiwari Abhishek Tiwari}

Yes, The Khan Academy IS the Future of Education (video) - (a) Chris_Evelo

Chris Evelo

Interesting presentations by youngsters at \#ISHG, but why do they all think a 15 min limit means you should speak faster, not say less?

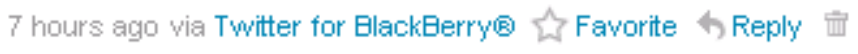
Delete

Tweets tagged with \#SHG

proflucia Lucia Regina Ribeiro

Chris Evelo talk at \#SHG 36th Ann Conf of the Indian Soc Hum Genet: Integrative systems biology. how to deal with large scale genetics data

1 hour ago 


\section{Dastricht University in Leading ing!}

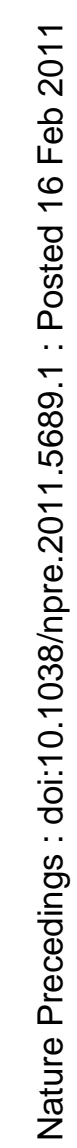
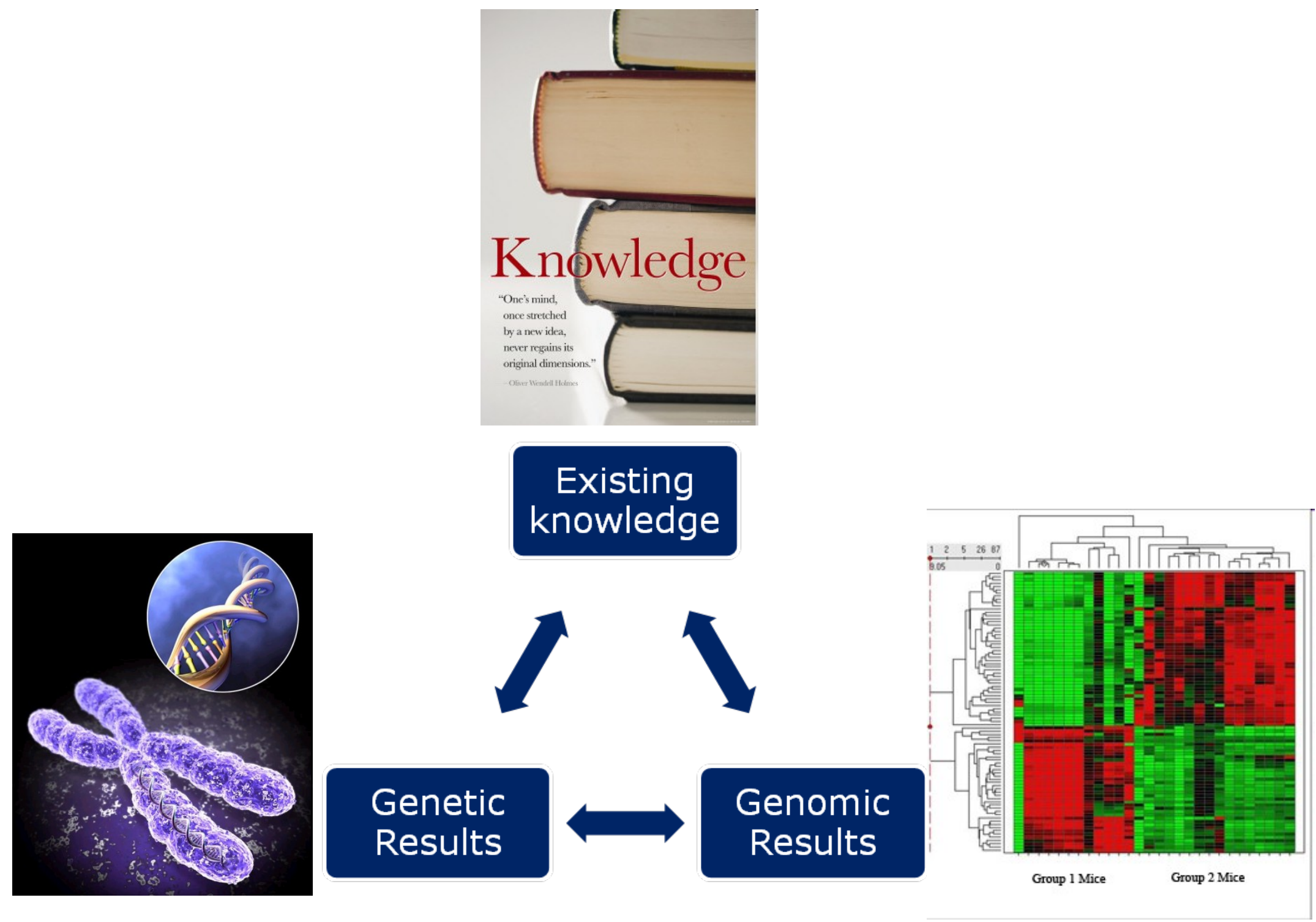

Faculty of Health, Medicine and Life Sciences 


\section{Dastricht University in Leanning!}

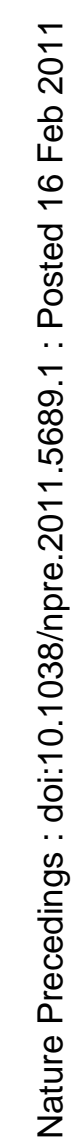

\section{Existing Knowledge Carefully Hidden in:}
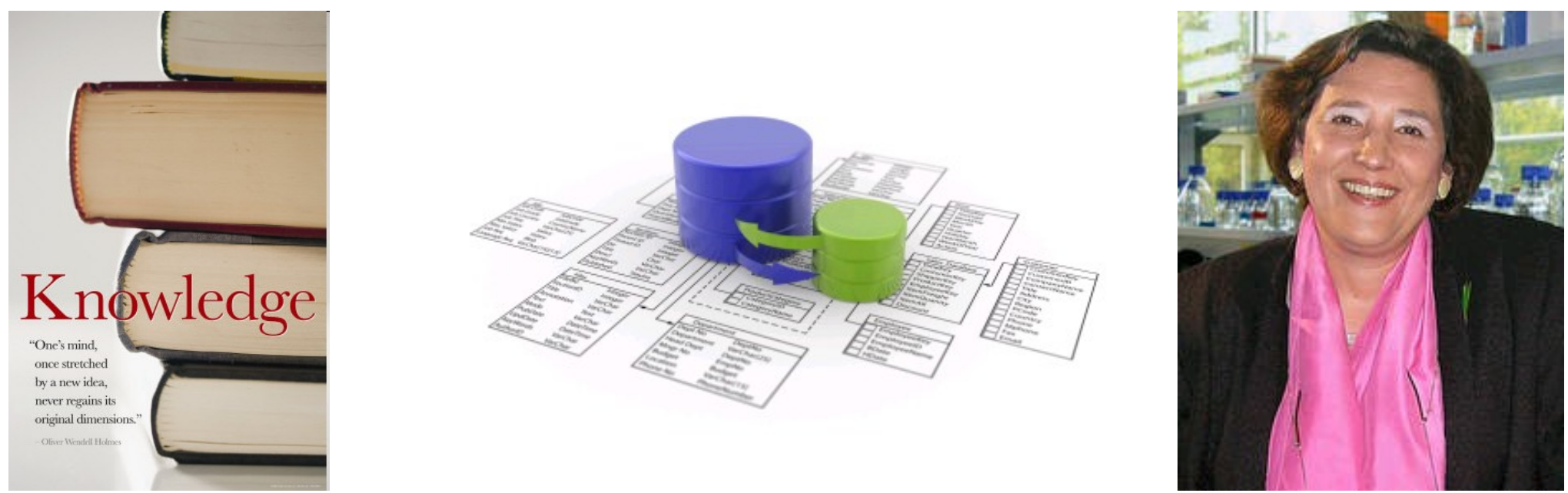


\section{Maastricht University in Leanning!}

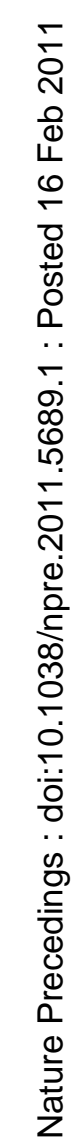

\section{Computers aren't good} at:

\section{Reading}

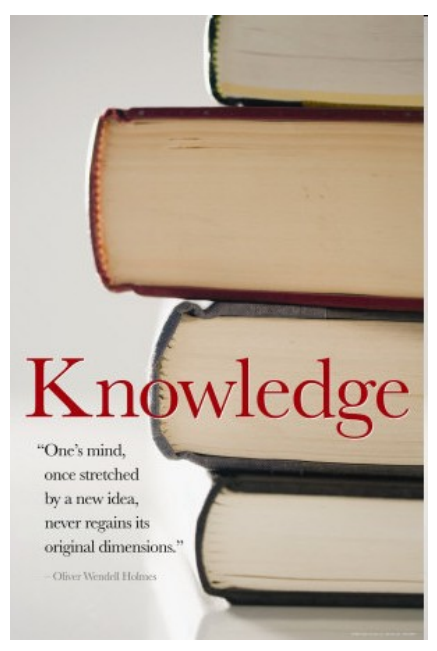

Listening

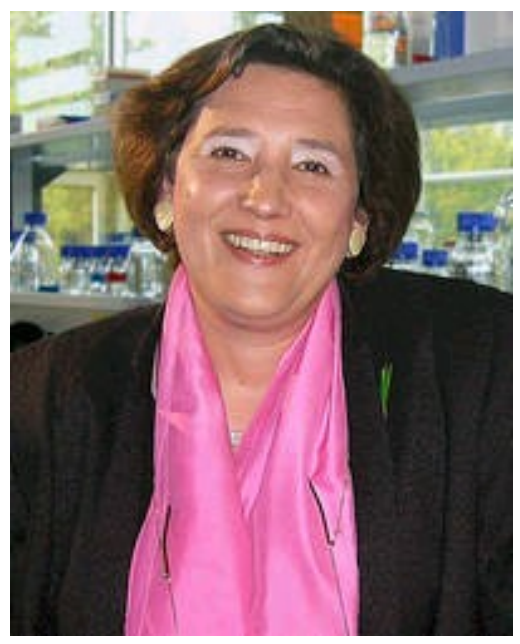




\section{Dastricht University in Leannming!}

\section{What do we really need? Well...}

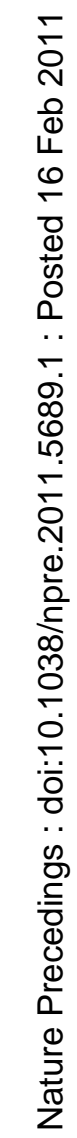

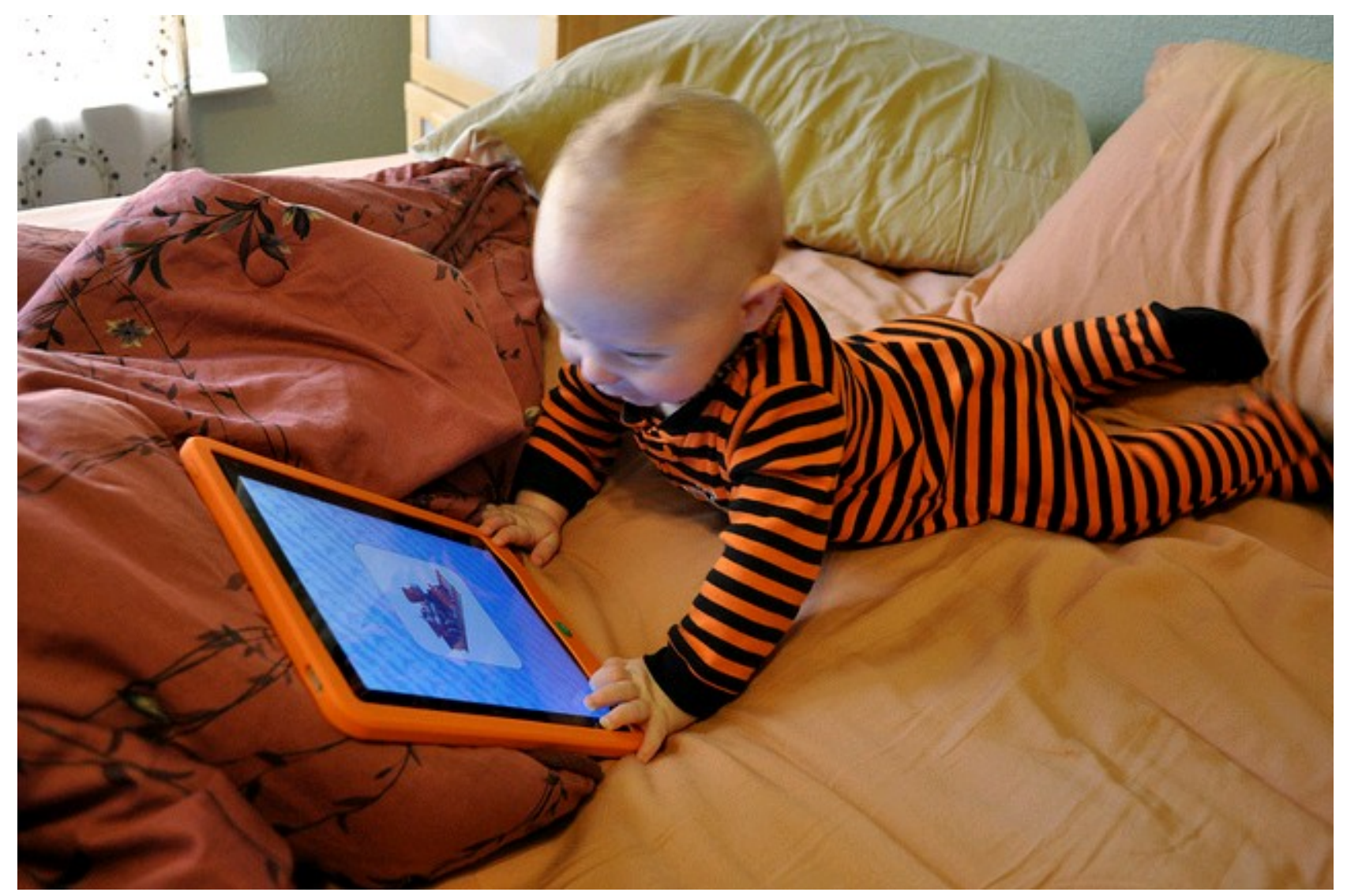




\section{Cardiomyopathy: Downregulated genes}

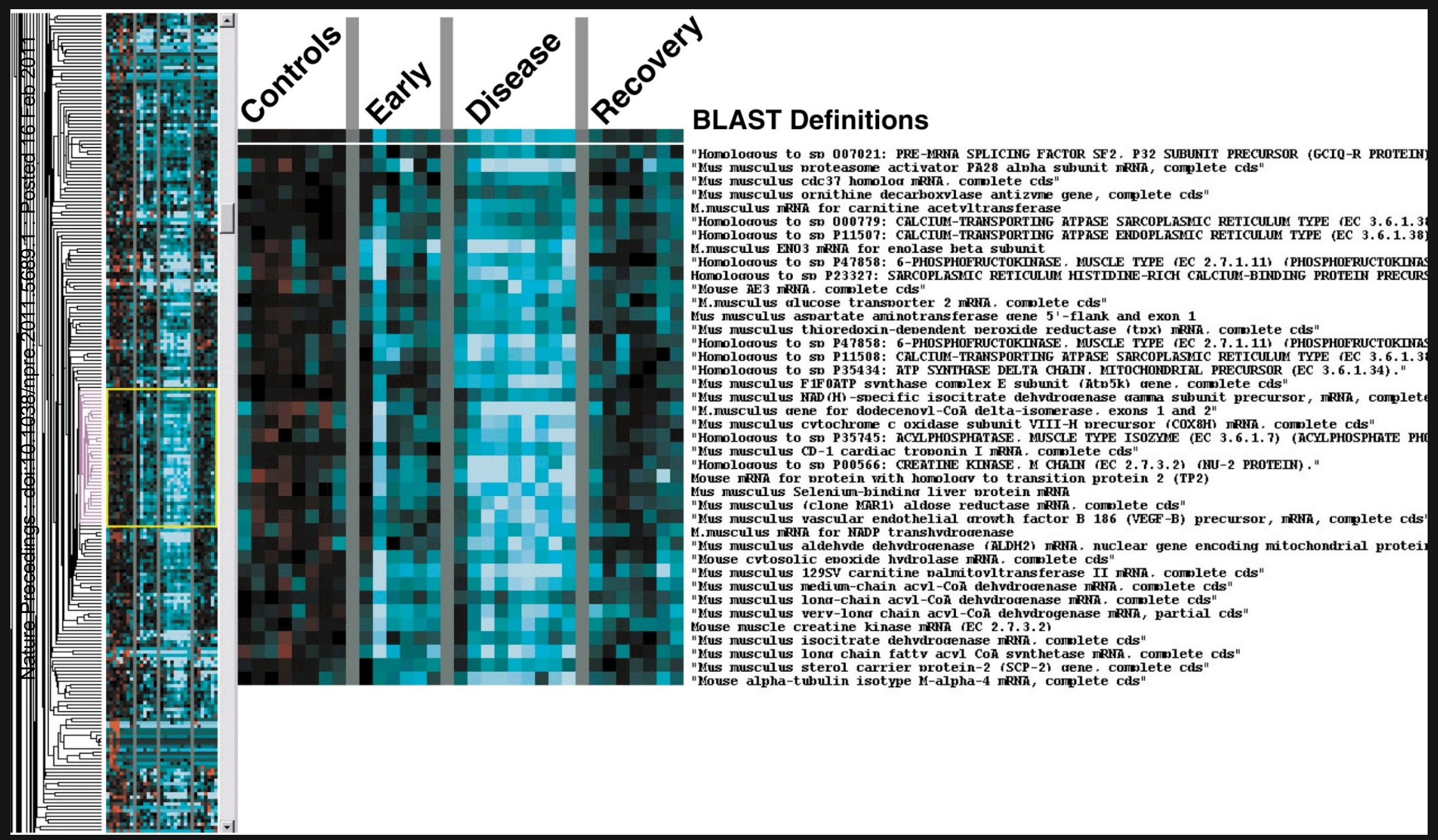




\section{Cardiomyopathy: Downregulated genes}

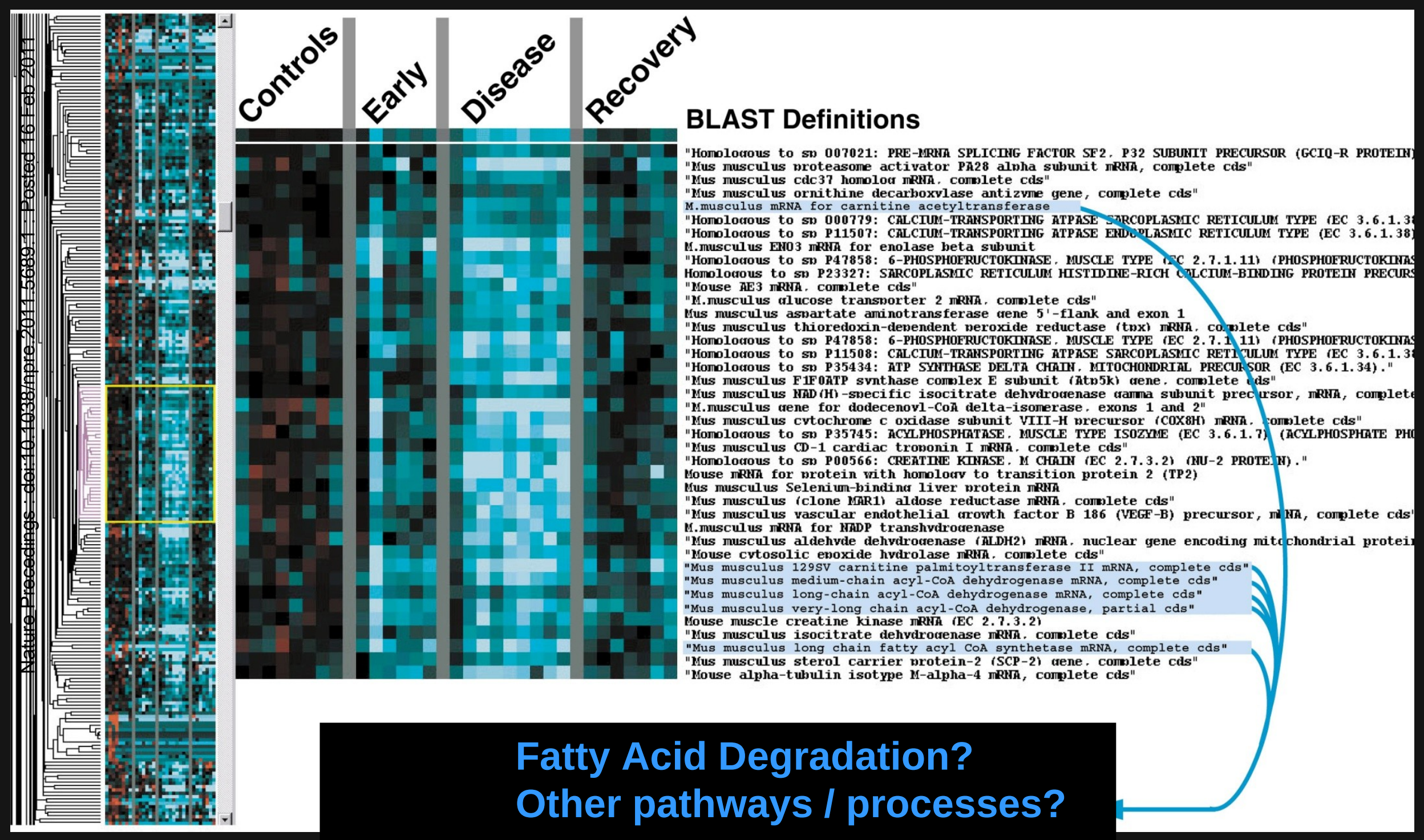


Find the pathways:

Biological processes in duodenal mucosa affected by glutamine administration

\begin{tabular}{|c|c|c|c|c|c|c|}
\hline \multirow[b]{2}{*}{ Pathway } & \multicolumn{5}{|c|}{ number of genes } & \multirow[b]{2}{*}{ Z Score } \\
\hline & Changed & Up & Down & Measured & Total & \\
\hline HS_Mitochondrial_fatty_acid_betaoxidation & 6 & 6 & 0 & 16 & 16 & 4.456 \\
\hline Hs_Electron_Transport_Chain & 17 & 17 & 0 & 85 & 105 & 4.278 \\
\hline Hs_Fatty_Acid_Synthesis & 5 & 5 & 0 & 21 & 22 & 2.757 \\
\hline Hs_Fatty_Acid_Beta-Oxidation & 6 & 6 & 0 & 31 & 32 & 2.424 \\
\hline Hs_mRNA_processing_Reactome & 16 & 6 & 10 & 118 & 127 & 2.402 \\
\hline Hs_Unsaturated_Fatty_Acid_Beta_Oxidation & 2 & 2 & 0 & 6 & 6 & 2.342 \\
\hline Hs_HSP70_and_Apoptosis & 4 & 4 & 0 & 18 & 18 & 2.299 \\
\hline Hs_Oxidative_Stress & 5 & 5 & 0 & 27 & 28 & 2.097 \\
\hline Hs_Fatty_Acid_Omega_Oxidation & 3 & 3 & 0 & 14 & 15 & 1.915 \\
\hline Hs_Proteasome_Degradation & 8 & 8 & 0 & 60 & 61 & 1.629 \\
\hline Hs_RNA_transcription_Reactome & 5 & 5 & 0 & 38 & 40 & 1.25 \\
\hline Hs_Irinotecan_pathway_PharmGKB & 2 & 1 & 1 & 12 & 12 & 1.154 \\
\hline $\begin{array}{l}\text { Hs_Synthesis_and_Degradation_of_Ketone_Bodi } \\
\text { es_KEGG }\end{array}$ & 1 & 1 & 0 & 5 & 5 & 1.023 \\
\hline
\end{tabular}


Du Maastricht University in Learning!
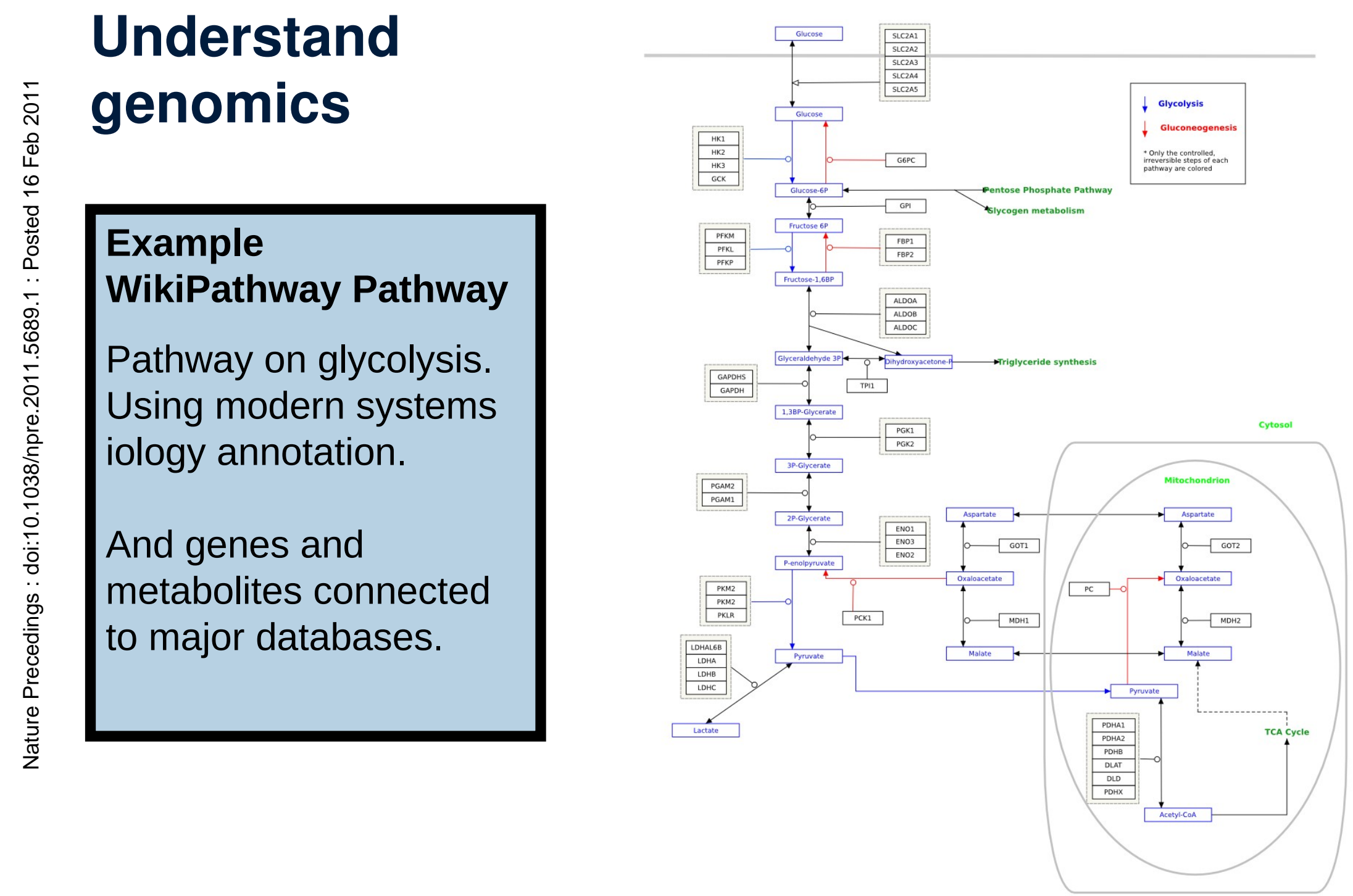



\section{Dastricht University Leading Leanning!}

\section{adding data $=$ adding colour}

\section{Example}

PathVisio result

Showing proteomics and transcriptomics results on the glycolysis pathway in mice liver after starvation.

[Data from Kaatje Lenaerts and Milka Sokolovic, analysis by Martijn van lersel]

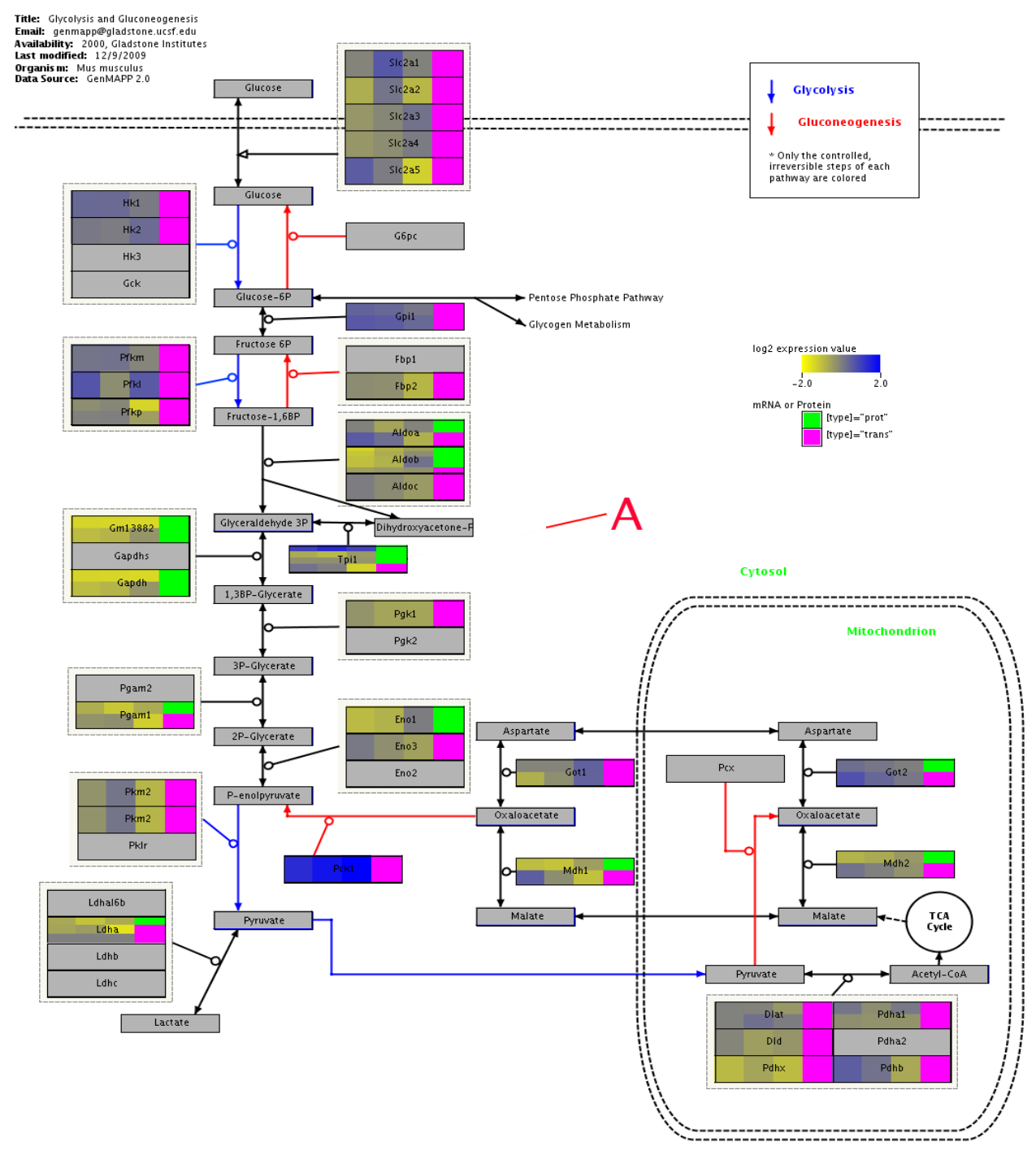




\section{Now we just need the Pathways}

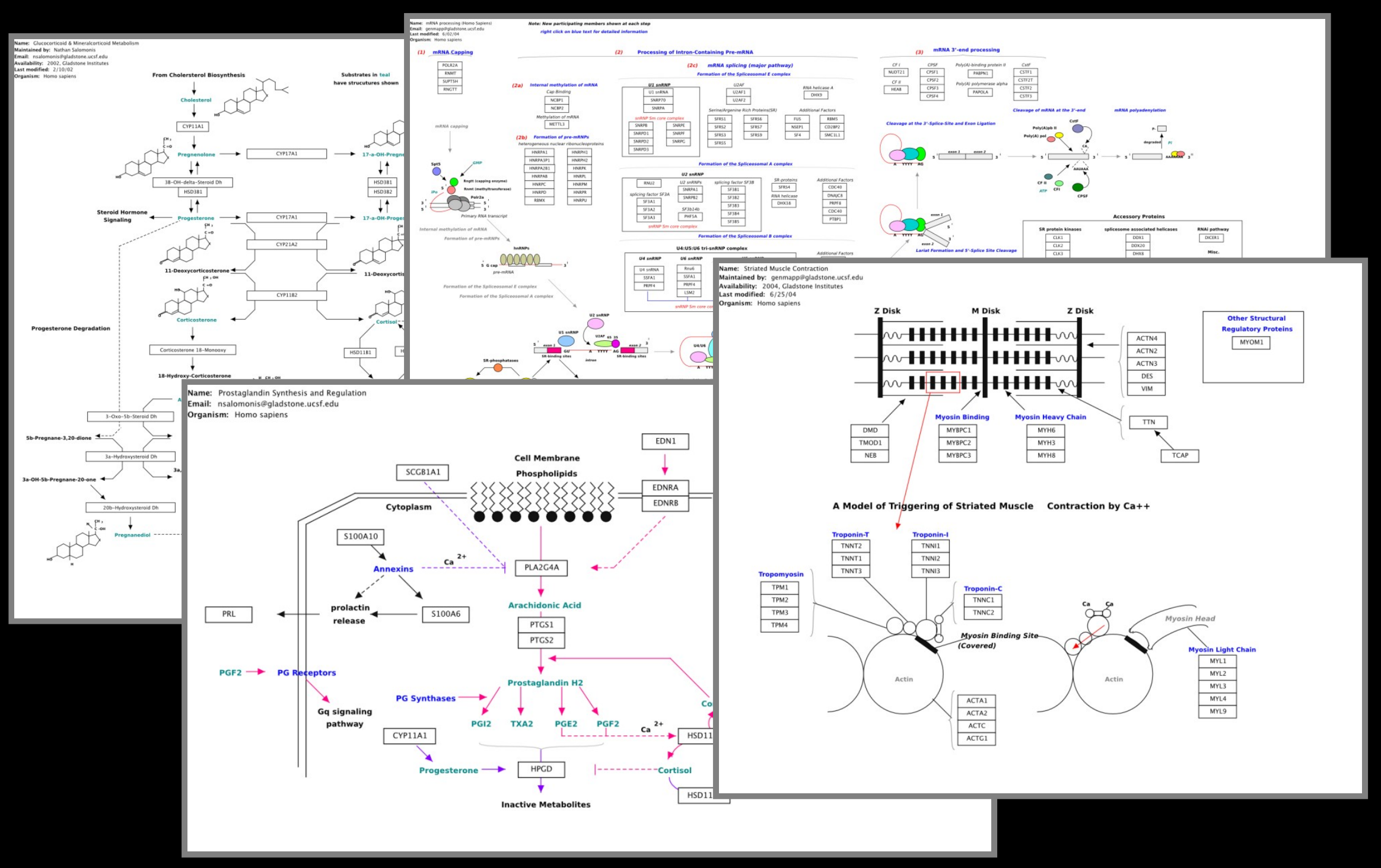




\section{WikiPathways}

- Public resource for biological pathways

- Anyone can contribute and curate

- More up-to-date representation of biological knowledge

WikiPathways: Pathway Editing for the People. Alexander R. Pico, Thomas Kelder, Martijn P. van lersel, Kristina Hanspers, Bruce R. Conklin, Chris Evelo. PLoS Biology 2008: 6: 7. e184

\section{Commentaries:}

Big data: Wikiomics. Mitch Waldrop. Nature 2008: 455, 22-25

We the curators. Allison Doerr. Nature Methods 2008: 5, 754-755

No rest for the bio-wikis. Ewen Callaway. Nature 2010: 468, 359-360 


\section{www.wikipathways.org}

\section{Welcome to WikiPathways ${ }^{\text {BETA }}$}

In the new tradition of Wikipedia, WikiPathways is an open, public platform dedicated to the curation of biological pathways by and for the scientific community. More about WikiPathways...

\section{Finding Pathways}

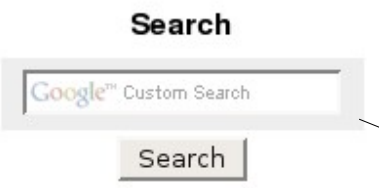

You can search by:

- Pathway name (Apoptosis)

- Gene or protein name (p53)

- Any page content (cancer)
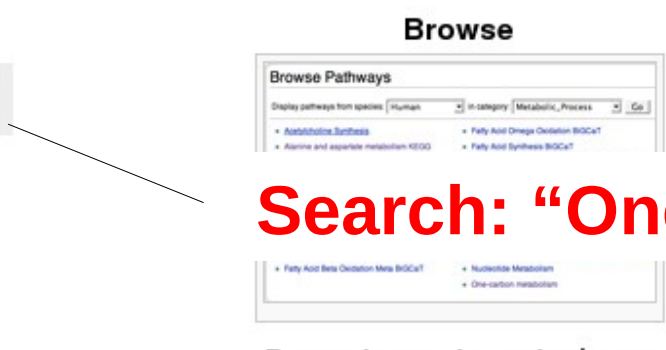

\section{Search: "One carbon"}

\section{Browse by species and category}

\section{Contributing New Pathways}

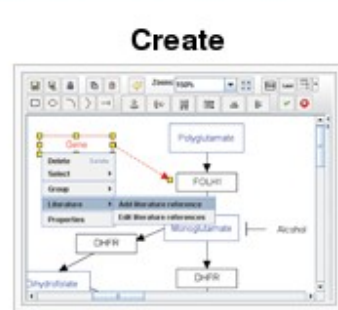

Create a new pathway page

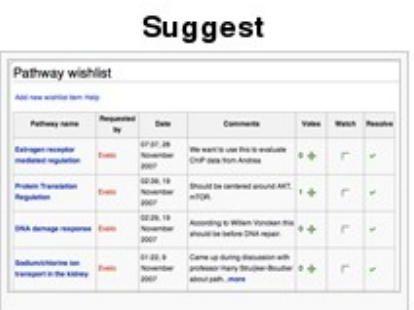

Add a pathway to the wish list

Sample Pathway Pages

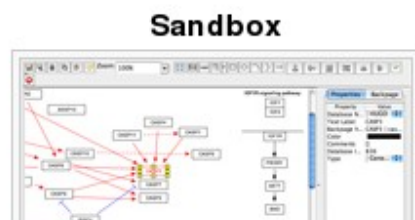

\section{Check out the following pages:}

- Show recent changes

- Show new pathways

- Show most edited pathways

- Show most viewed pathways

\section{Today's featured pathway}

Pentose Phosphate Pathway (Caenorhabditis elegans)

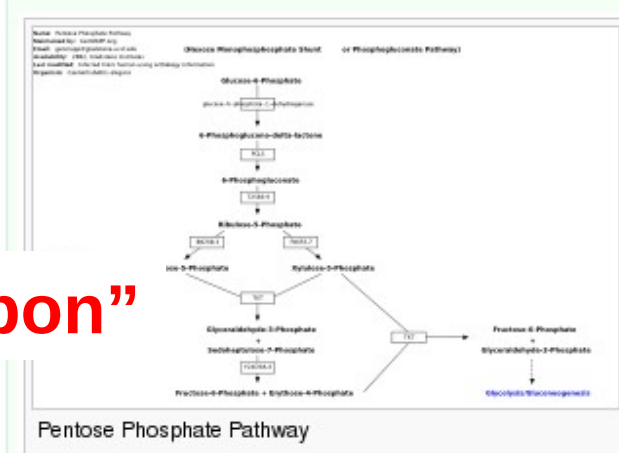

Pentose Phosphate Pathway

\section{New!}

- WikiPathways won the application showcase at the NBIC BioRange Consortium Meeting 툰?

- Pathway Wish List

- New embedded pathway editor

- Batch download page

- Visual diff tool for comparing pathway versions

Coming Soon...

- Converted content from KEGG and Reactome

- Tagging pathways with terms from Gene Ontology and other biological ontologies

\section{Statistics}

- There are $\mathbf{4 9 7}$ pathways

- Number of pathways (and unique genes) per species:

$\begin{array}{ll}\text { Homo sapiens: } & 103(3436) \\ \text { Rattus norvegicus: } & 105(3049) \\ \text { Mus musculus: } & 109 \text { (3725) }\end{array}$


(2) > C X I

[2] Most Visited (3) Getting Started \$I Latest Headlines

\section{find pathways - wikiPathways}

\section{Find pathways}

Search for: one carbon

ALLSPECIES $\quad$ Search

Tip: use AND, OR, *, ?, parentheses orquotes

\section{3 pathways found}

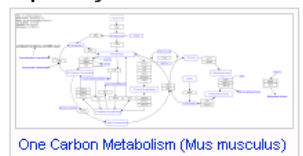

One Carbon Metabolism (Mus musculus)

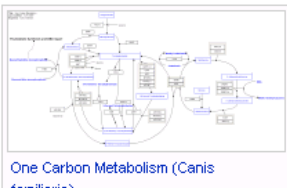

One Carbon
farmiliaris)

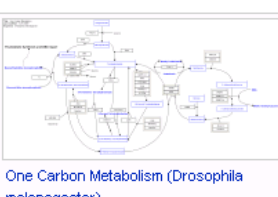

One Carbon Met
melanogaster)

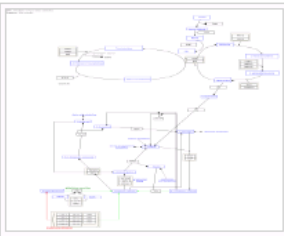

Glutathione and one carbon metabolism (Mus musculus)

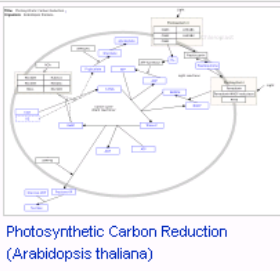

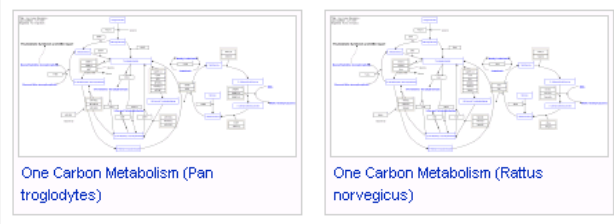

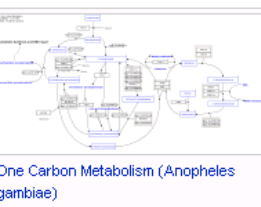

One Carbo

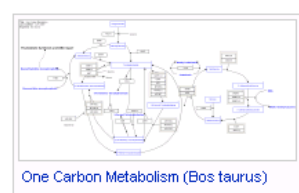

One Carbon Metabolism (Bos taurus)

\section{Click}

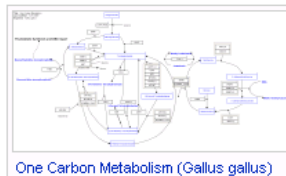

One Carbon Metabolism (Gallus gallus)

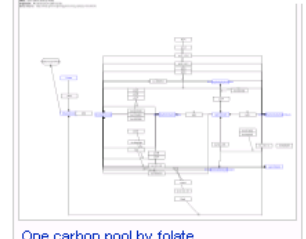

(Mycobacteriunn tuberculosis)

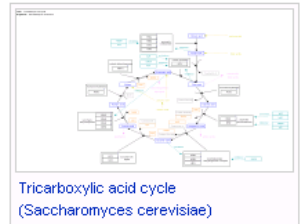

Trinitrotoluene degradation $\underline{\bar{C}}=\underline{-}$ mays) (Arabidopsis thaliana)

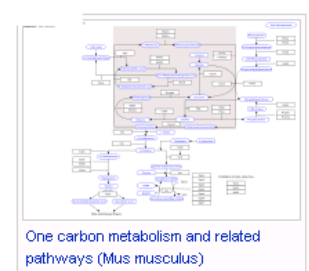

One carbon metabolism and relat
pathways (Mus musculus)

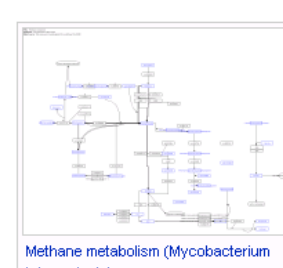

Methane metabolism (Mycobacterium

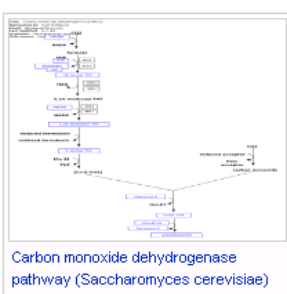

pathway (Saccharomyces cerevisiae)

Glyoxylate and dicarboxylate metabolism (Mycobacterium tuberculosis)

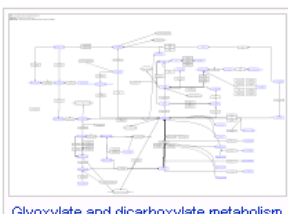

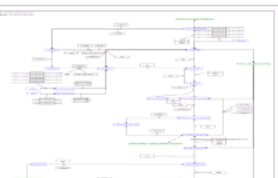




\section{Pathway:Homo sapiens:One-carbon metabolism}



\section{Contents [hide]}

1 Description

2 Bibliography

3 Categories

4 Download files

4.1 Image format

4.2 Data formats

4.3 Actions

4.4 Batch

5 History

6 Pathway Info 6.1 DataNodes

\section{Description}

This one-carbon metabolism pathway is centered around folate. Folate is the primary methyl-group donor for processes such as DNA methylation reactions, nucleotide synthesis and DNA repair mechanisms. An important pathway for any study related to folate or DNA methylation.

Differential methylation (e.g. hypermethylation of tumor suppressors) as well as disturbances in nucleotide synthesis and repair, are associated with several forms of cancer. There are also indications that hypermethylation is involved in the progression of adenomas to cancer.

\section{Bibliography}

1. Hazra A, Wu K, Kraft P, Fuchs CS, Giovannucci EL, and Hunter DJ. Twenty-four non-synonymous polymorphisms in the one-carbon metabolic pathway and risk of colorectal adenoma in the Nurses' Health Study. Carcinogenesis 2007 Jul; 28(7) 1510-9. 


\section{Editing}

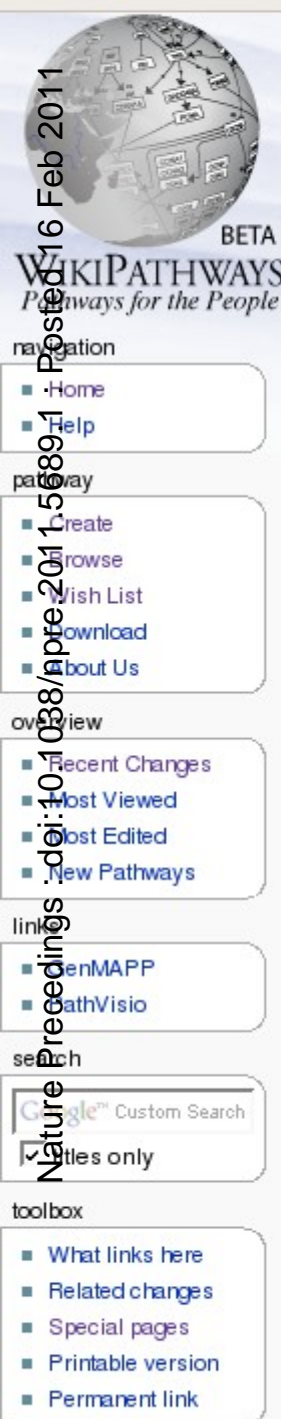

pathway discussion edit history delete move protect urwatch

\& Thomas my talk my preferences my watchlist my contributions logout Pathway:Mus musculus:Circadian clock pathway

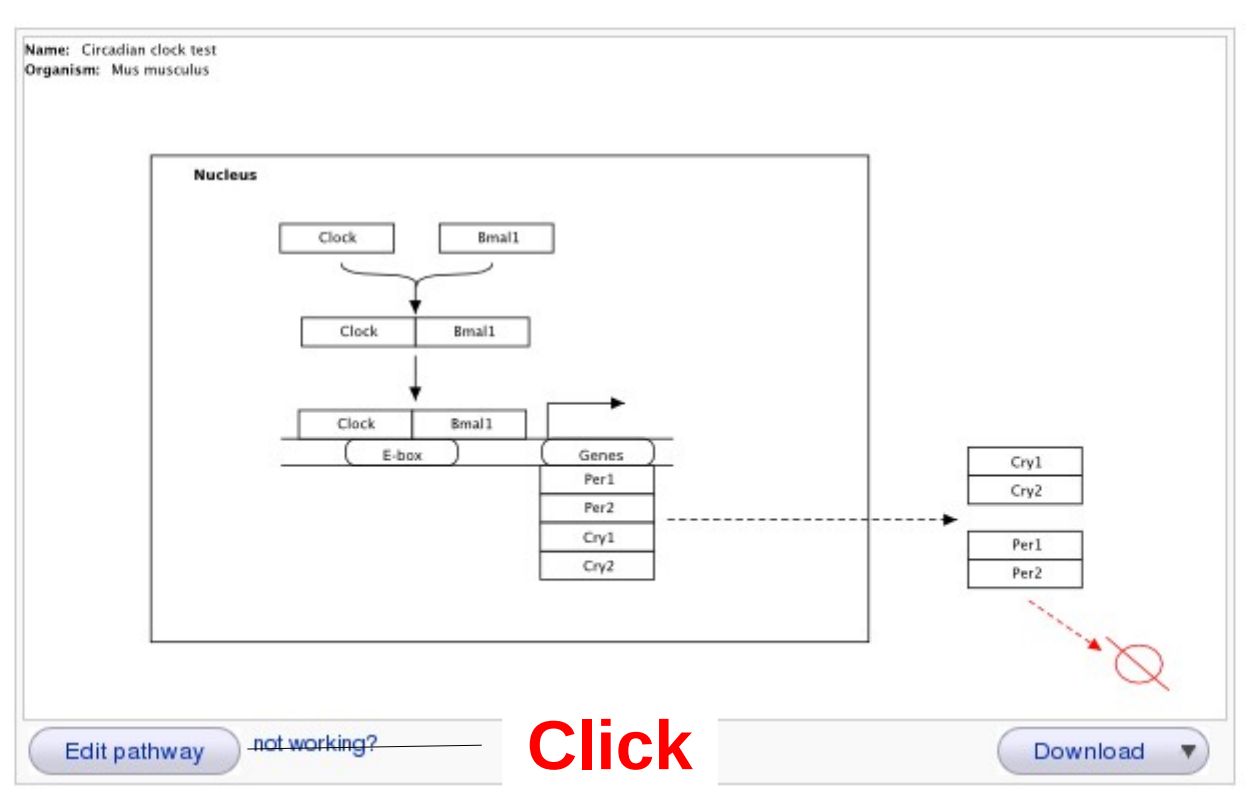

Contents [hide]

1 Description

2 Bibliography

3 Categories

4 Download files

4.1 Image formats

4.2 Data formats

4.3 Actions

4.4 Batch

5 History

6 Pathway Info 6.1 DataNodes

\section{Description}

The circadian clock is a molecular mechanism that maintains the cell' metabolism, physiology and behaviour. This is a simplified version of

\section{Login needed}

Registration by e-mail address

nes, involved in 


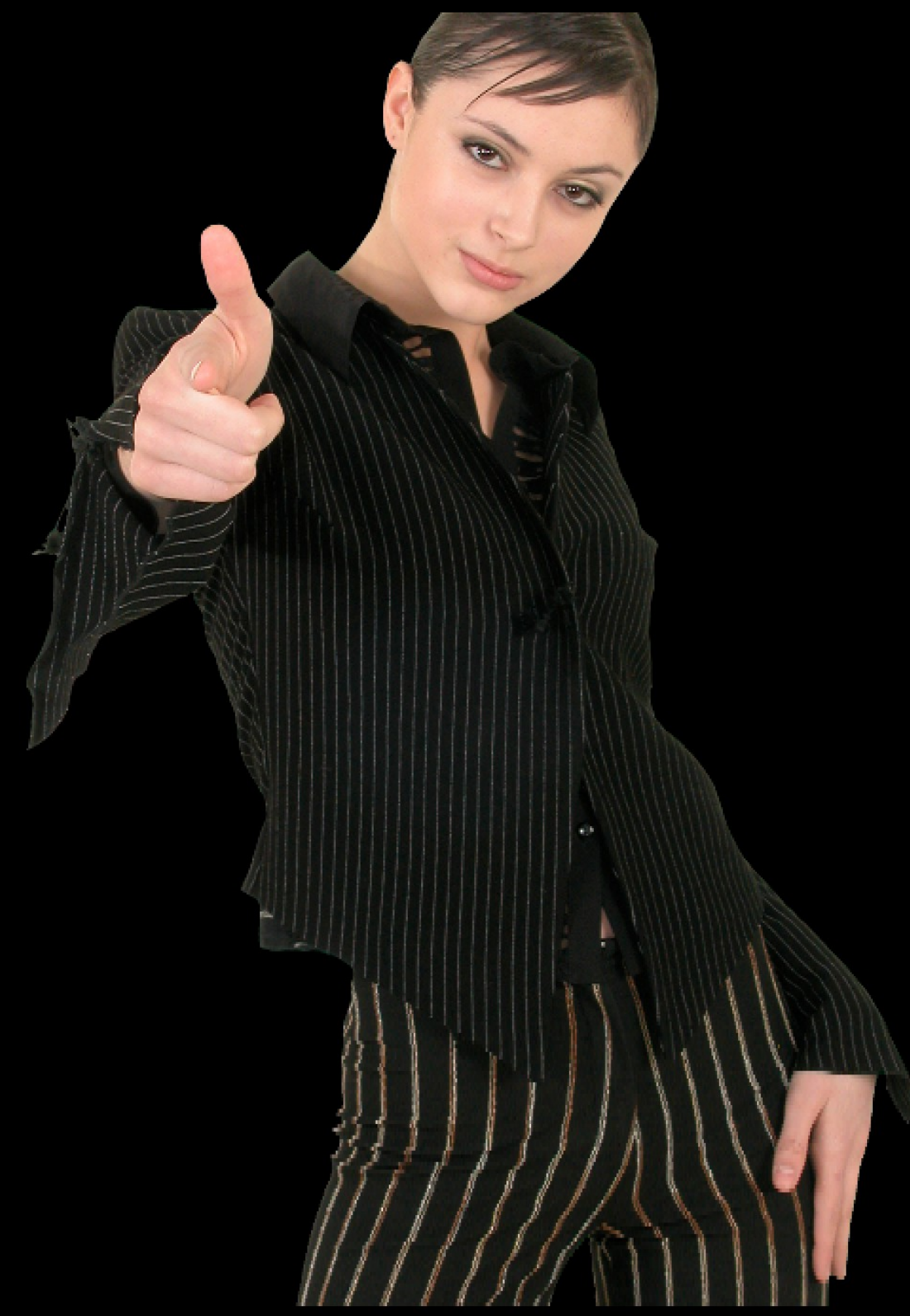




\section{Draw the proteins and interactions}

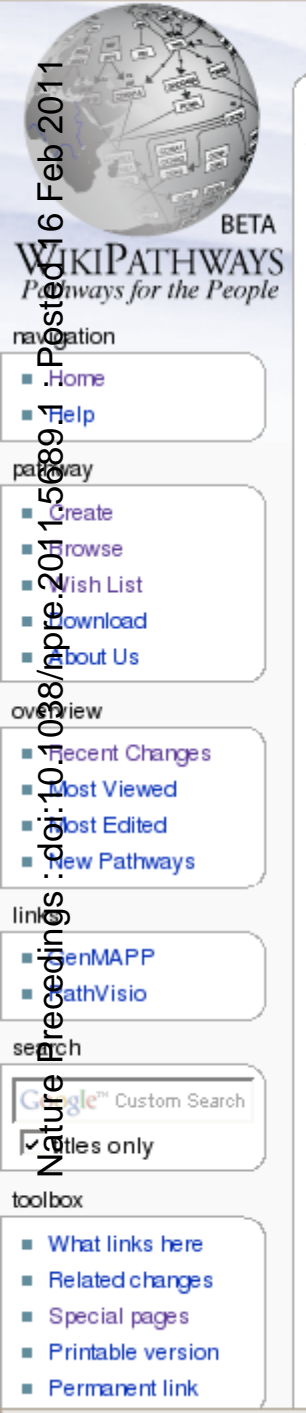

pathway discussion edit history delete move protect urwatch

\& Thomas my talk my preferences my watchlist my contributions logout

Pathway:Mus musculus:Circadian clock pathway

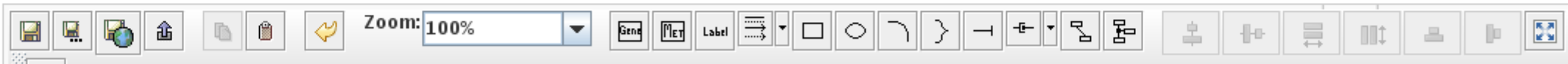
$\boldsymbol{x}$

Name: Circadian clock test

Organis m: Mus musculus

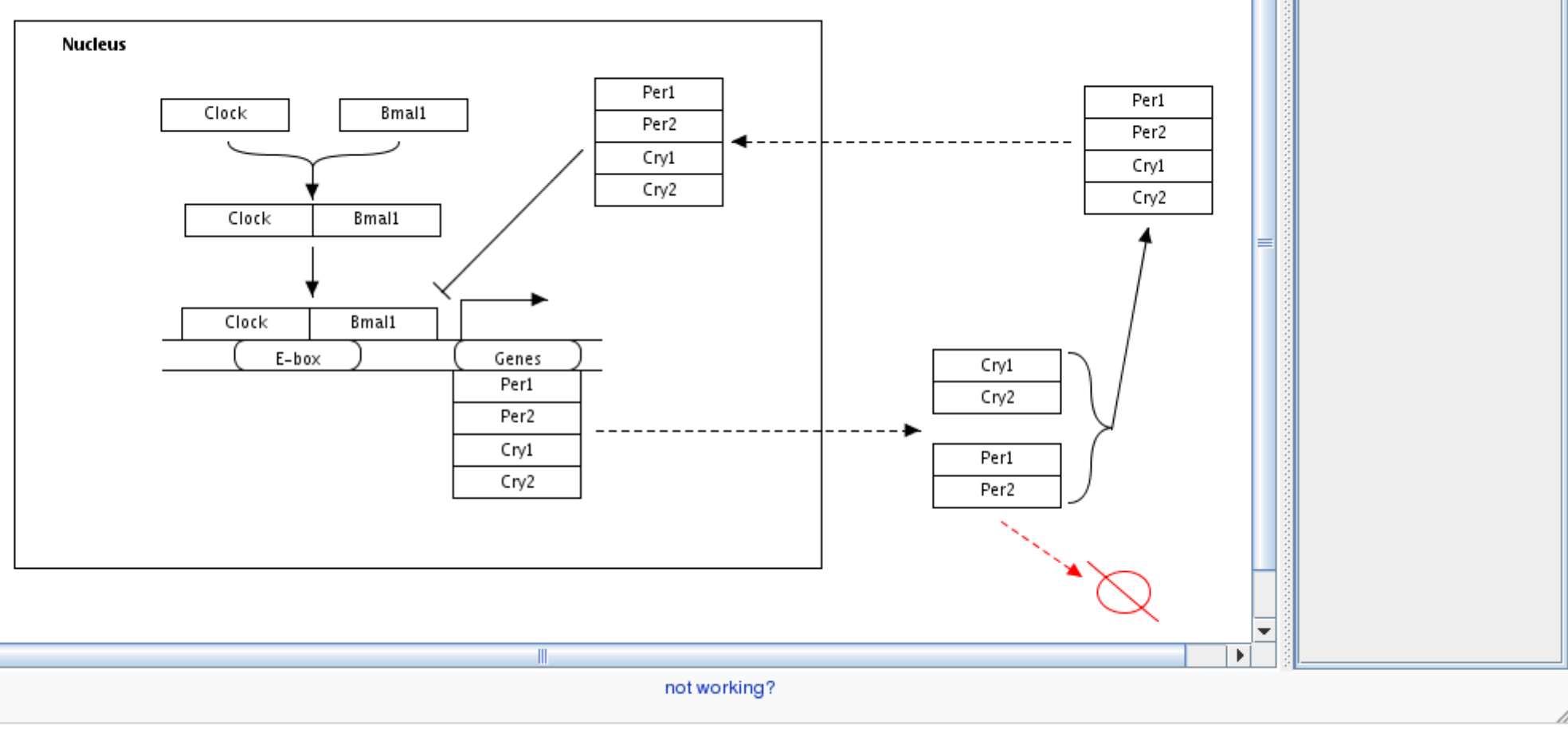

not working?

- Properties Backpage Property Value 


\section{How to ever do data visualization?}

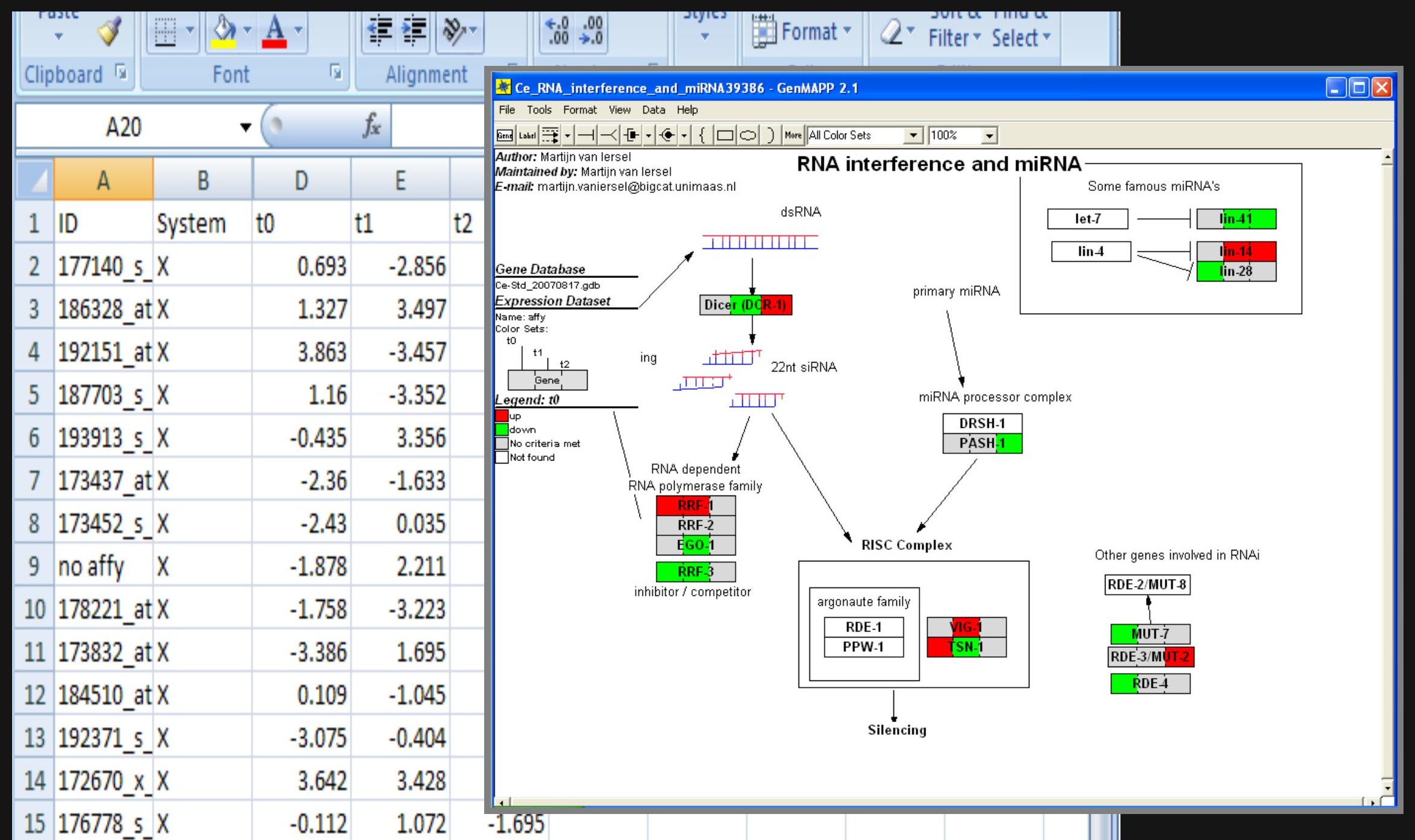




\section{Connect to Genome Databases}

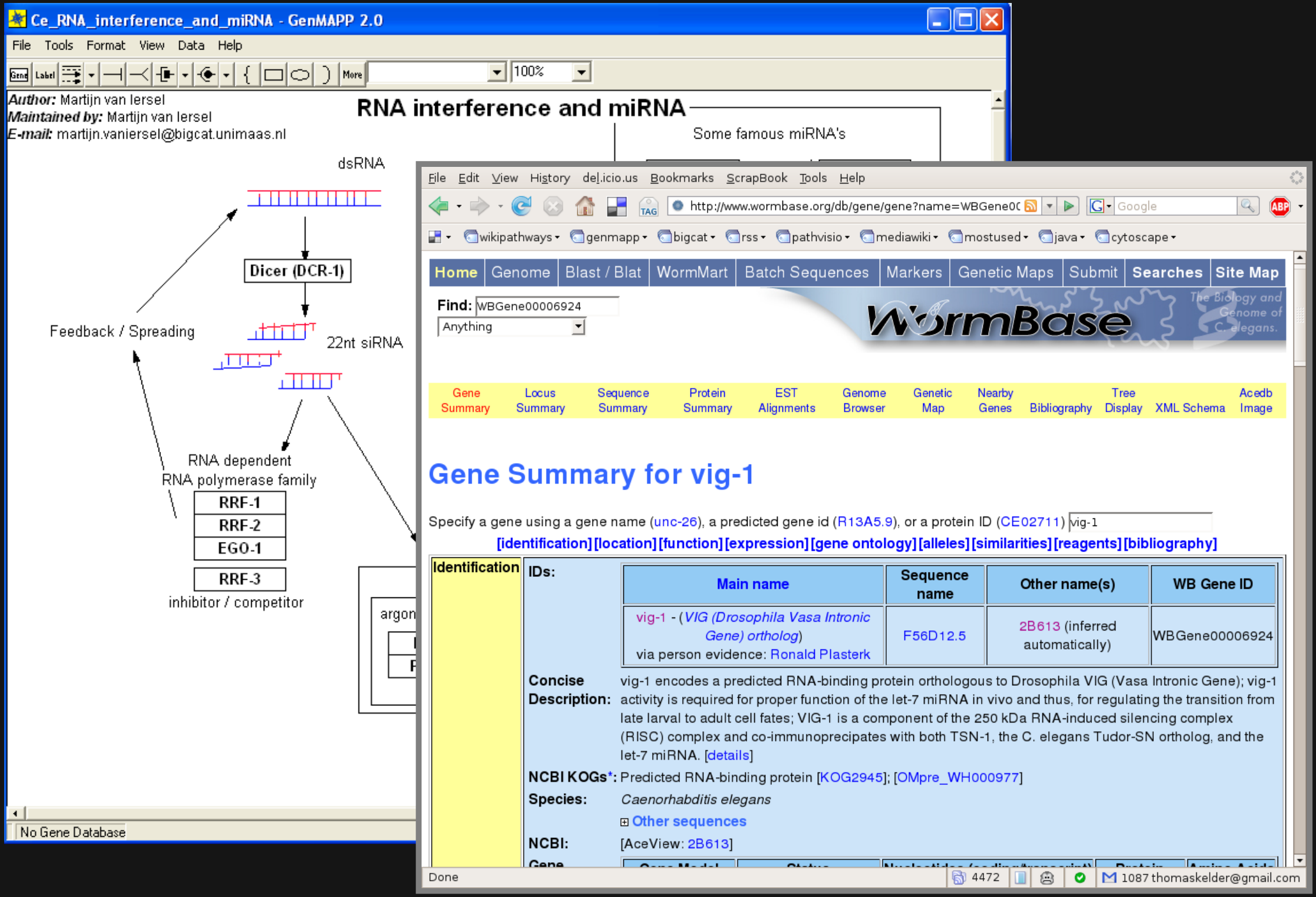




\section{Double click to annotate the proteins}

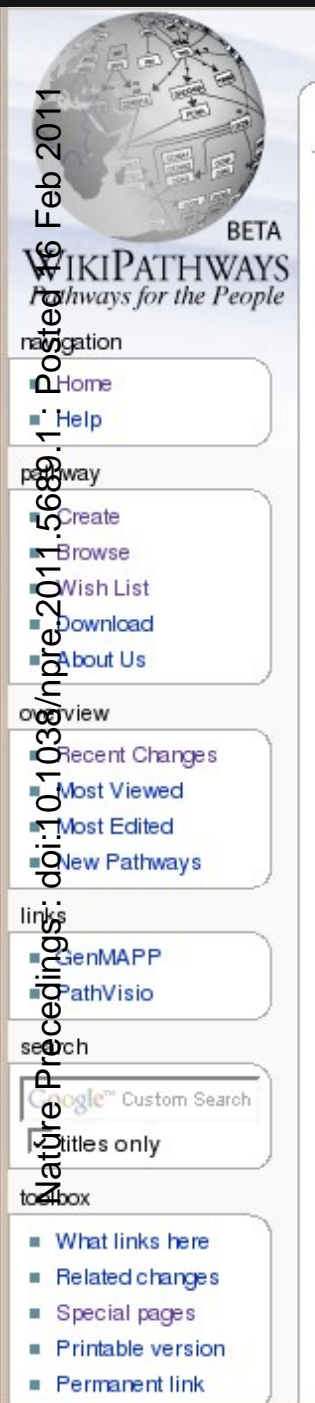

pathway discussion edit history delete move protect urwatch

\& Thomas my talk my preferences my watchlist my contributions log out Pathway:Mus musculus:Circadian clock pathway

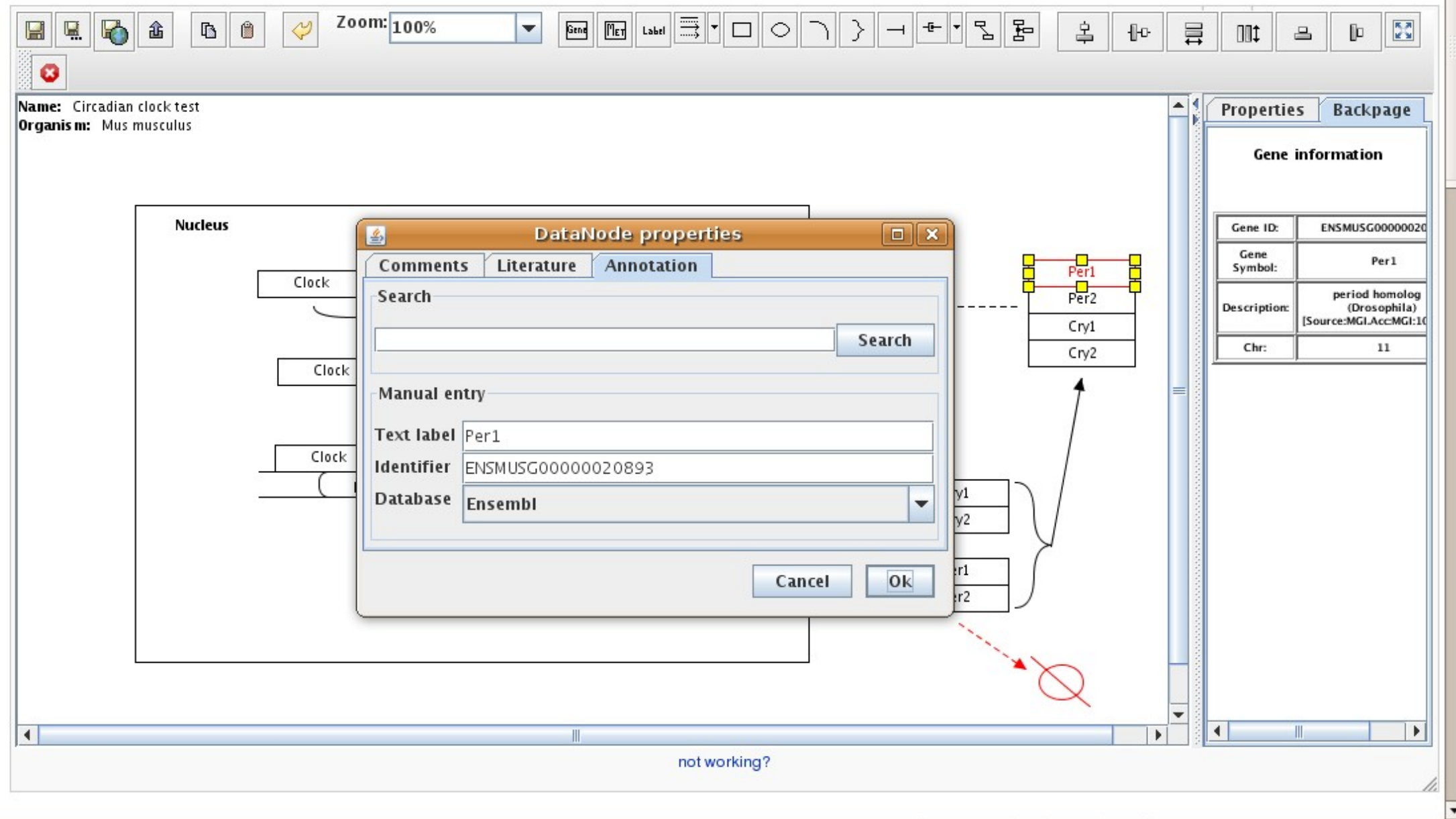




\section{Download}

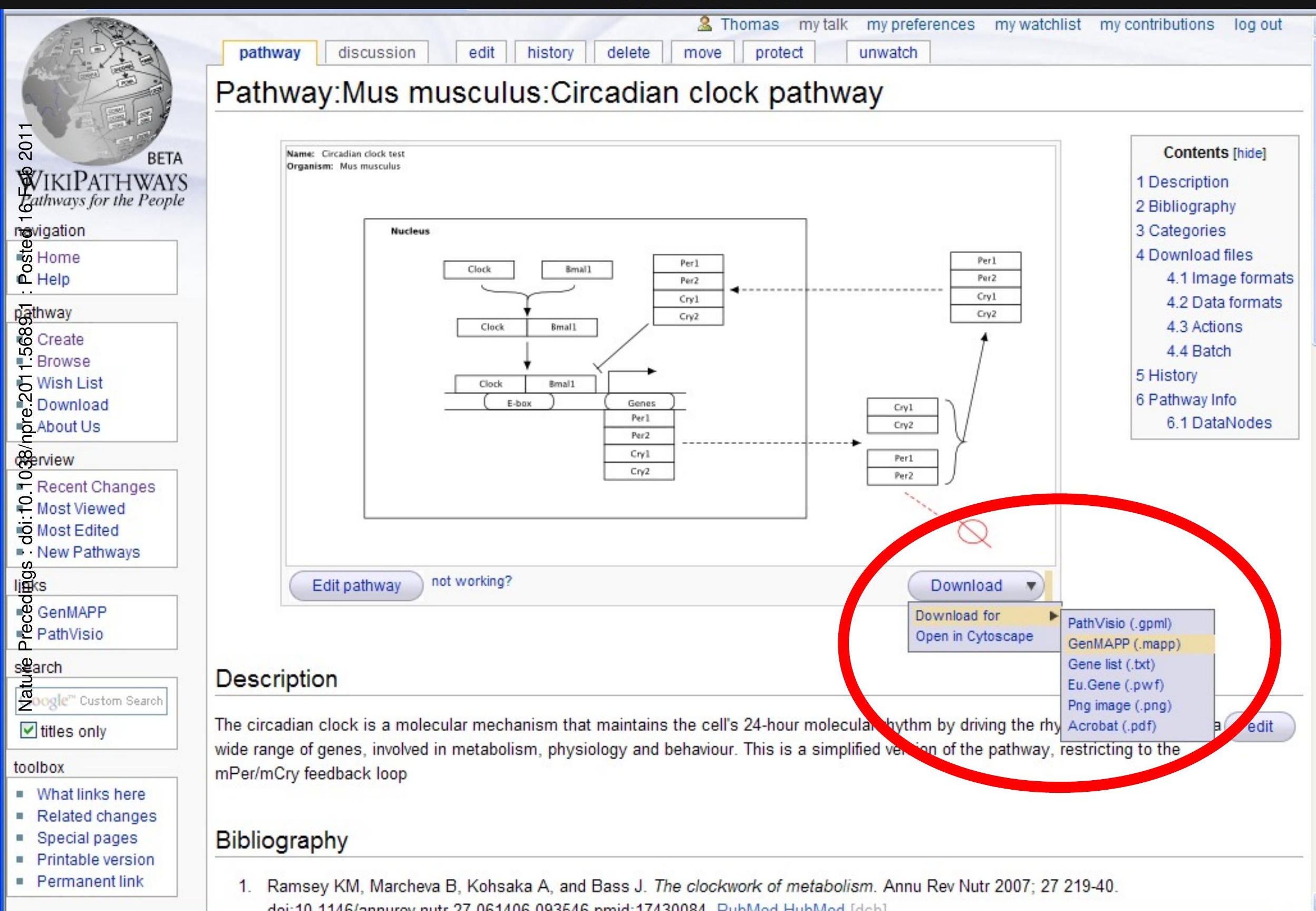




\section{Cytoscape visualization used to group}

PPS1

Liver

All pathways

กิ

㐫

o Pathways with high z-score grouped together.

: Explains why there are \% relatively few significant genes, but many pathways $\stackrel{\approx}{\approx}$ with high z-score.

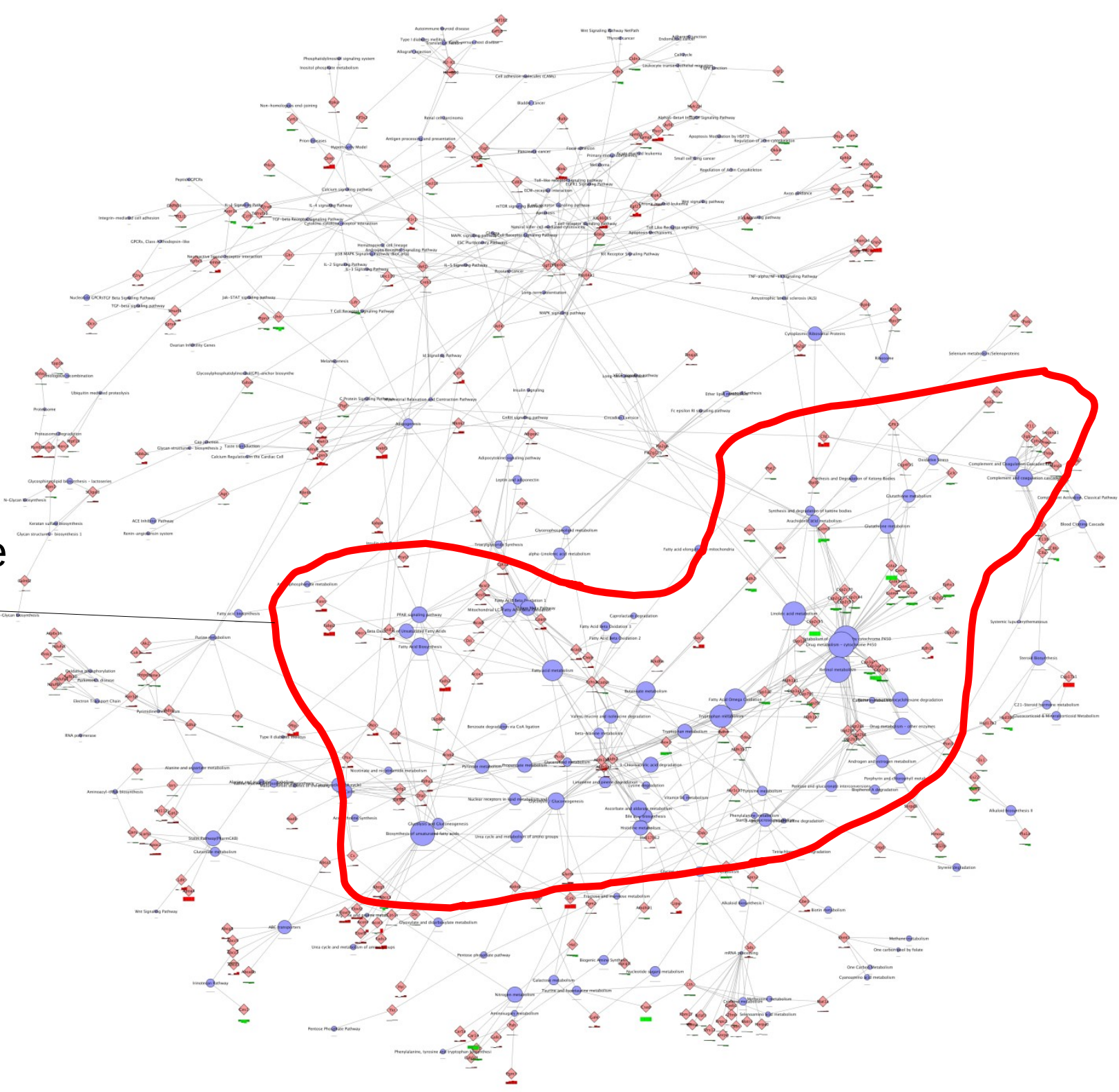




\section{Dastricht University in Leanning!}

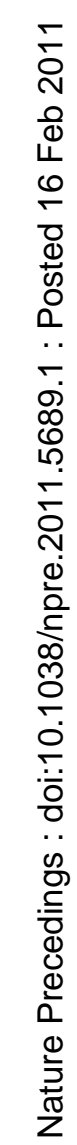

\section{Existing Knowledge Carefully Hidden in:}
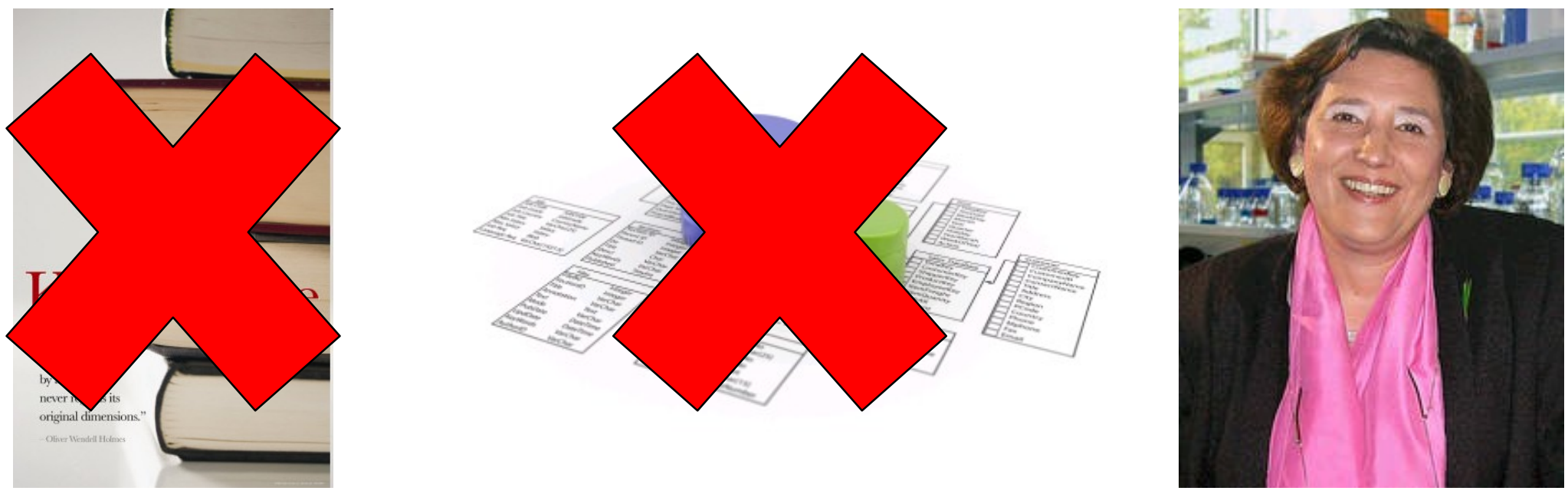


\section{Assisted content generation}

Suggestions from:

- Compound sources (HMDB)

- Gene resources (UniProt, IntAct)

- Pathways \& processes (KEGG, GO, local)

- Text mining

- Semantic web data stores 


\begin{tabular}{l} 
Order \\
Select \\
Literature \\
Properties \\
PpP \\
\hline
\end{tabular}

Oxaloacetate
HMDB Suggestions

PHASAR Suggestions

KEGG

WikiPathways (local) Suggestions

Bind Suggestions

\section{Property} Property

Center $\mathrm{X}$

Center $Y$

Color

Comments

Database Identifier

Database Name

Height

Text Labe

Type

Width

W

1965.0

[]

2828026

300.0

LAT

I GeneProduct

1200.0 


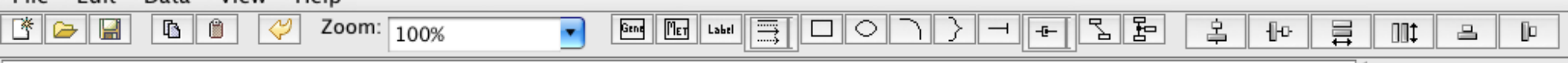

$\div$

o

0
$\mathbb{C}$
5

c

尺

.
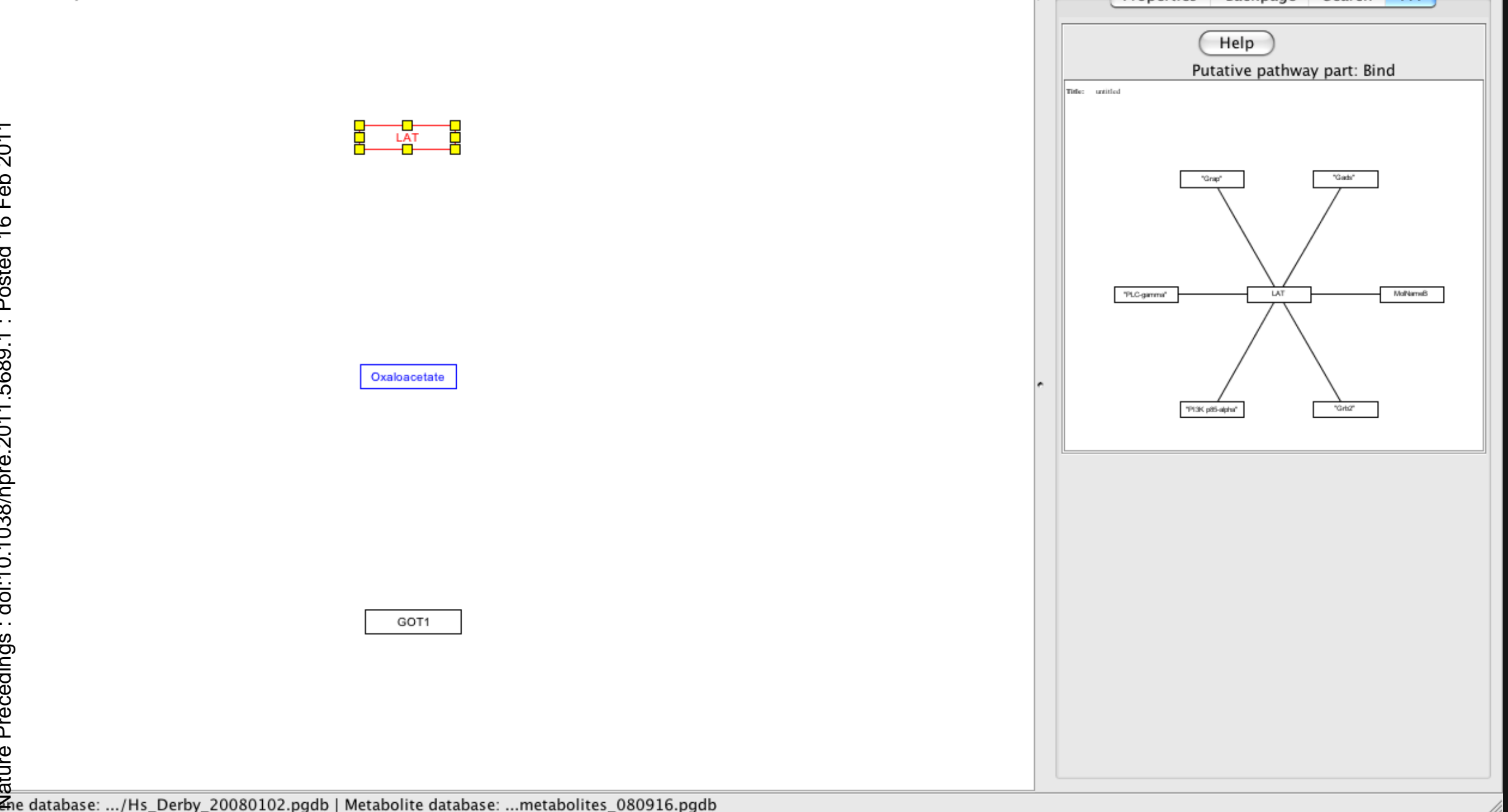

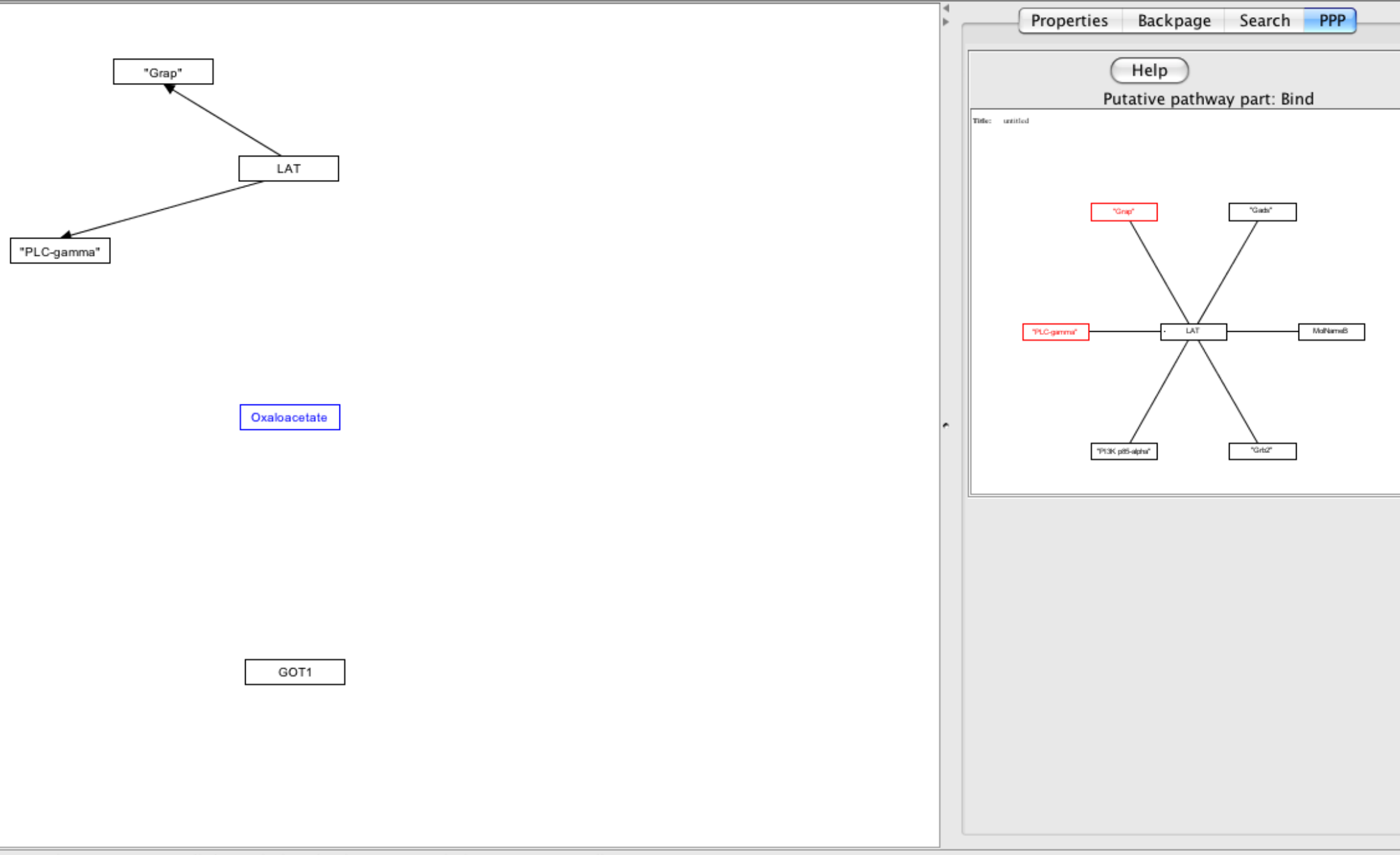


\section{Dastricht University in Leading ing!}

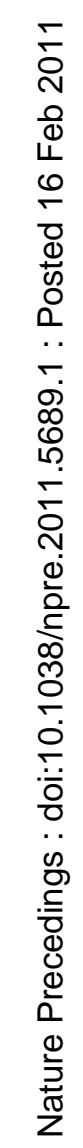
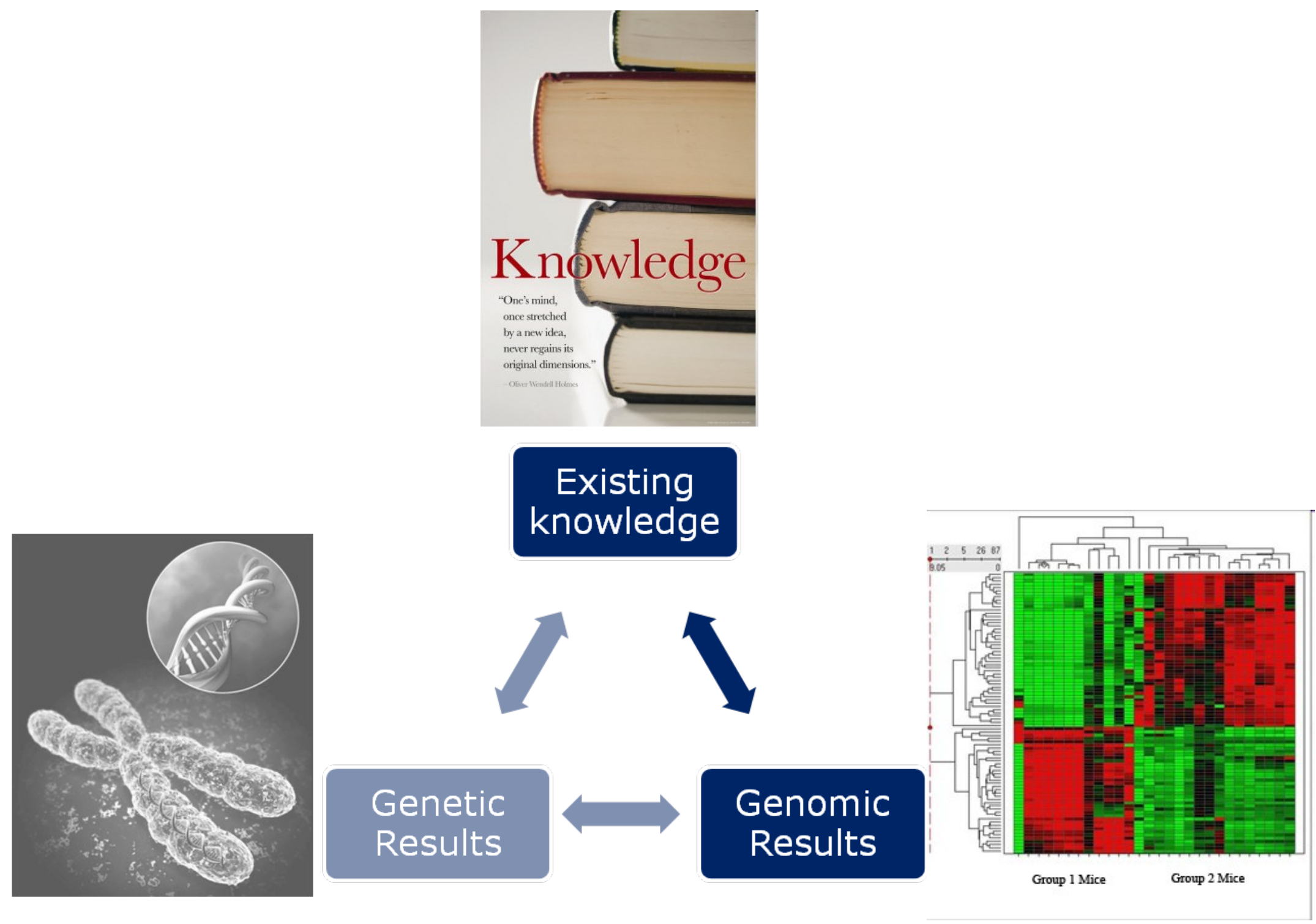

Faculty of Health, Medicine and Life Sciences 


\section{Dastricht University in Leading ing!}

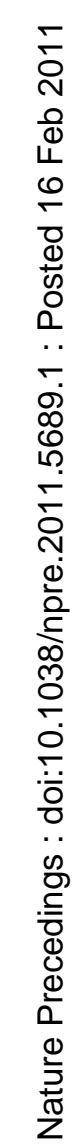
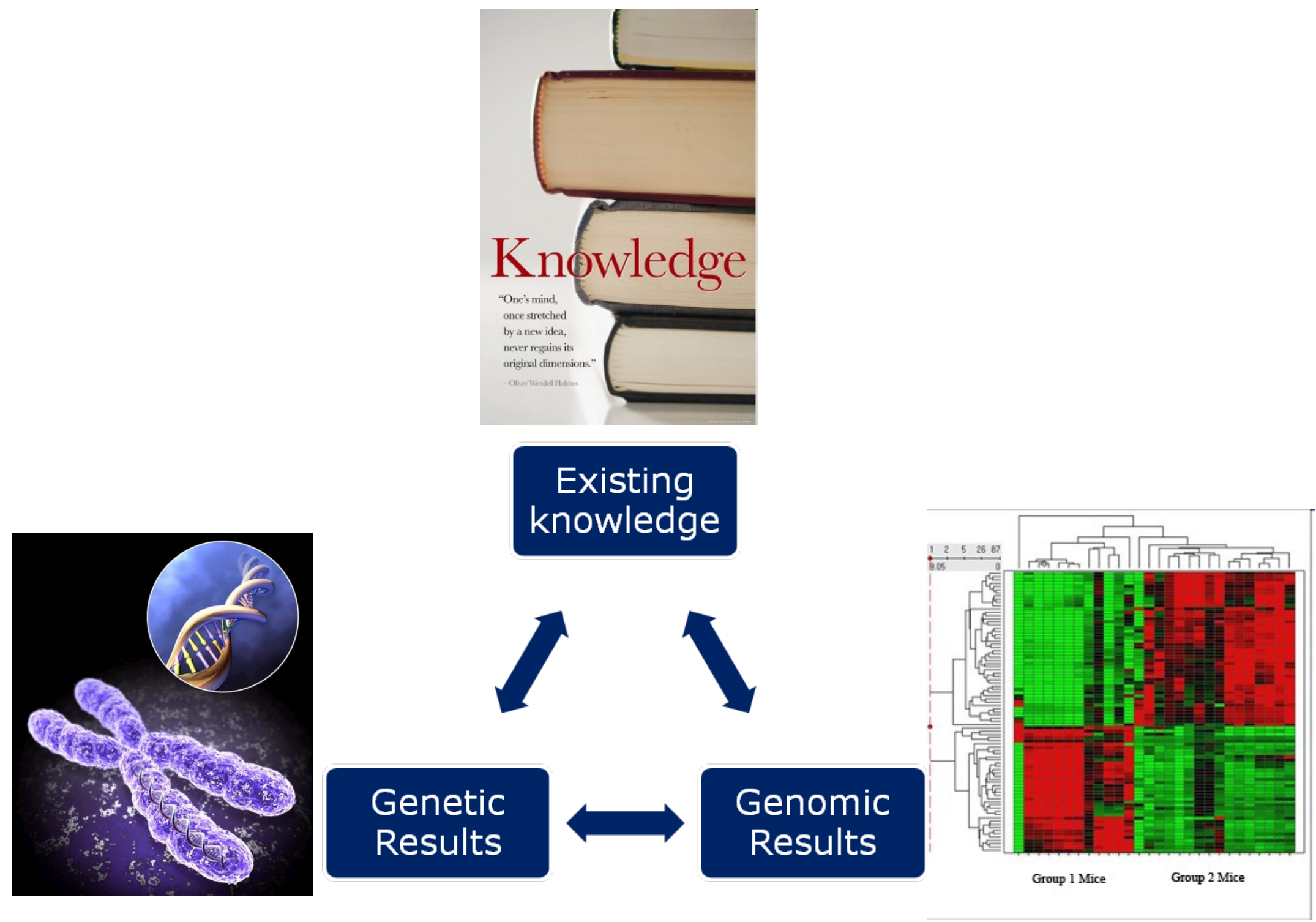

Faculty of Health, Medicine and Life Sciences 


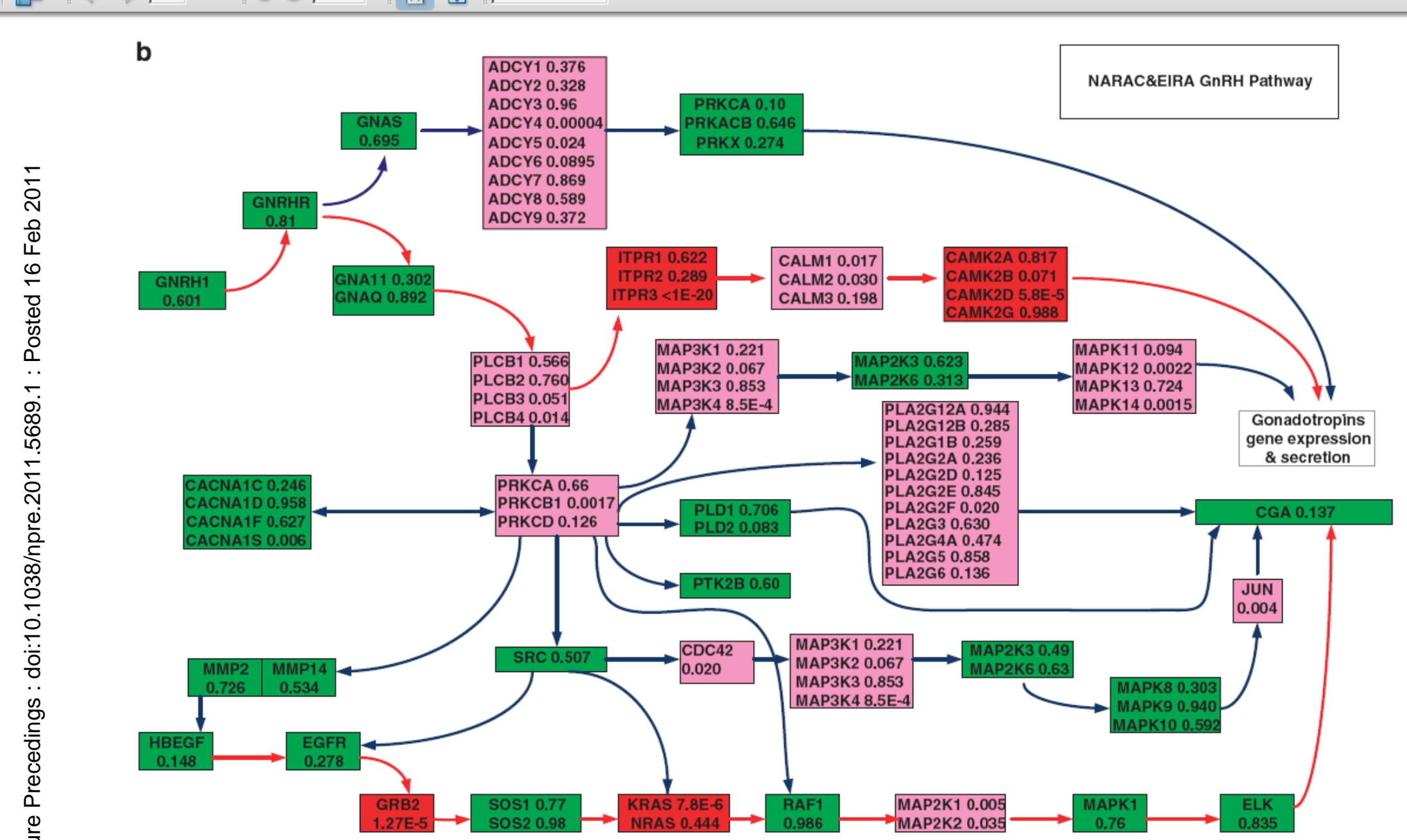

Figure $1 P$-values of genes in GnRH pathway for RA. (a) $P$-values of genes in GnRH pathway for RA in WTCCC studies. Blocks containing significant genes are in red color, blocks containing mild significant genes are in light red color and blocks containing no significant genes are in green color. (b) $P$-values of genes in GnRH pathway for RA in NARAC and EIRA studies. Blocks containing significant genes are in red color, blocks containing mild significant genes are in light red color and blocks containing no significant genes are in green color. 


\section{Problem: Identifier Mapping}

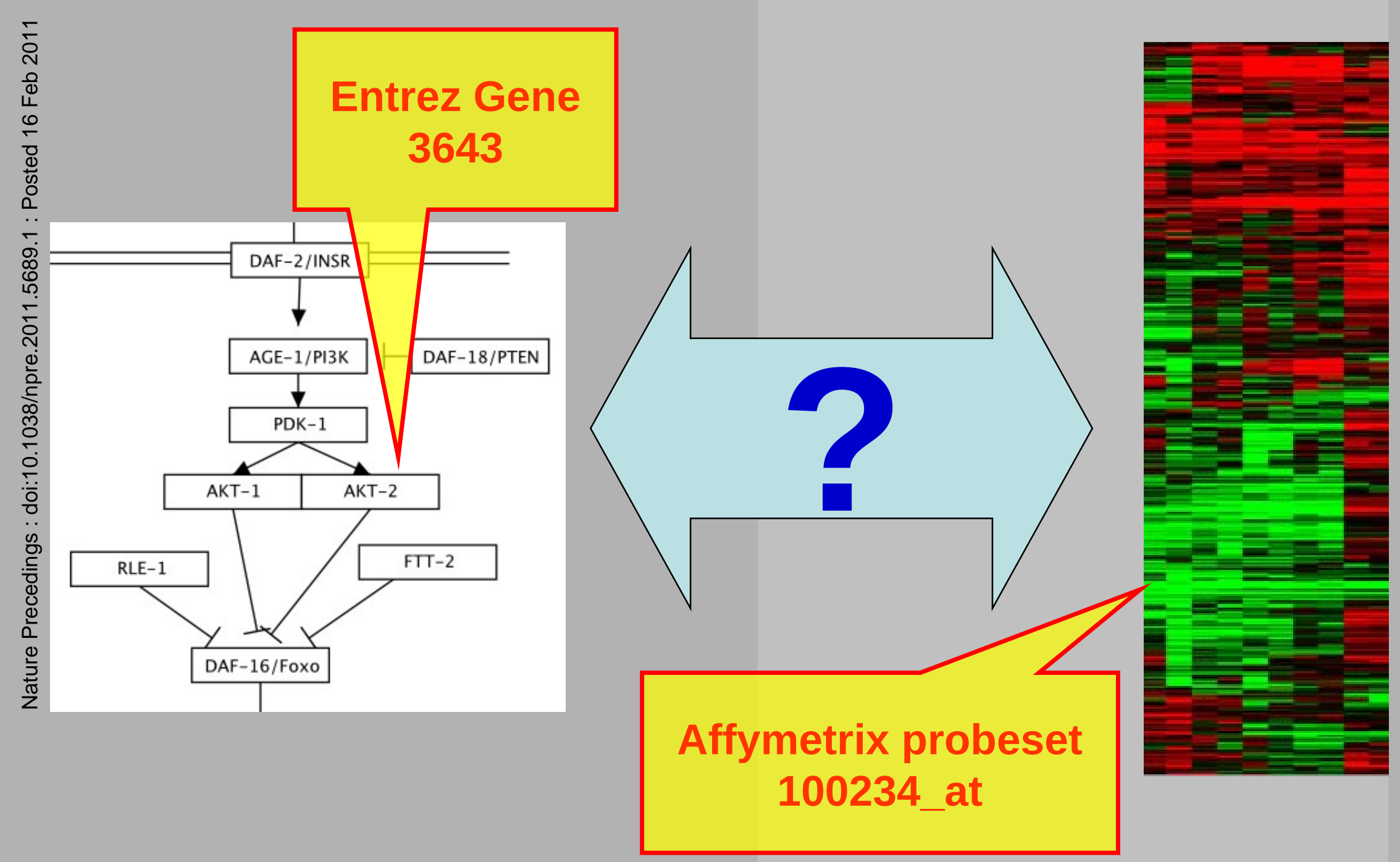




\section{BridgeDB: Abstraction Layer}

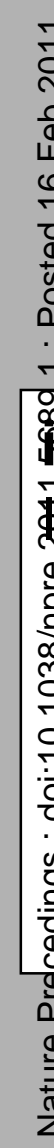

nnterface DMapper

兘 class

IDMapperRdb

relational database

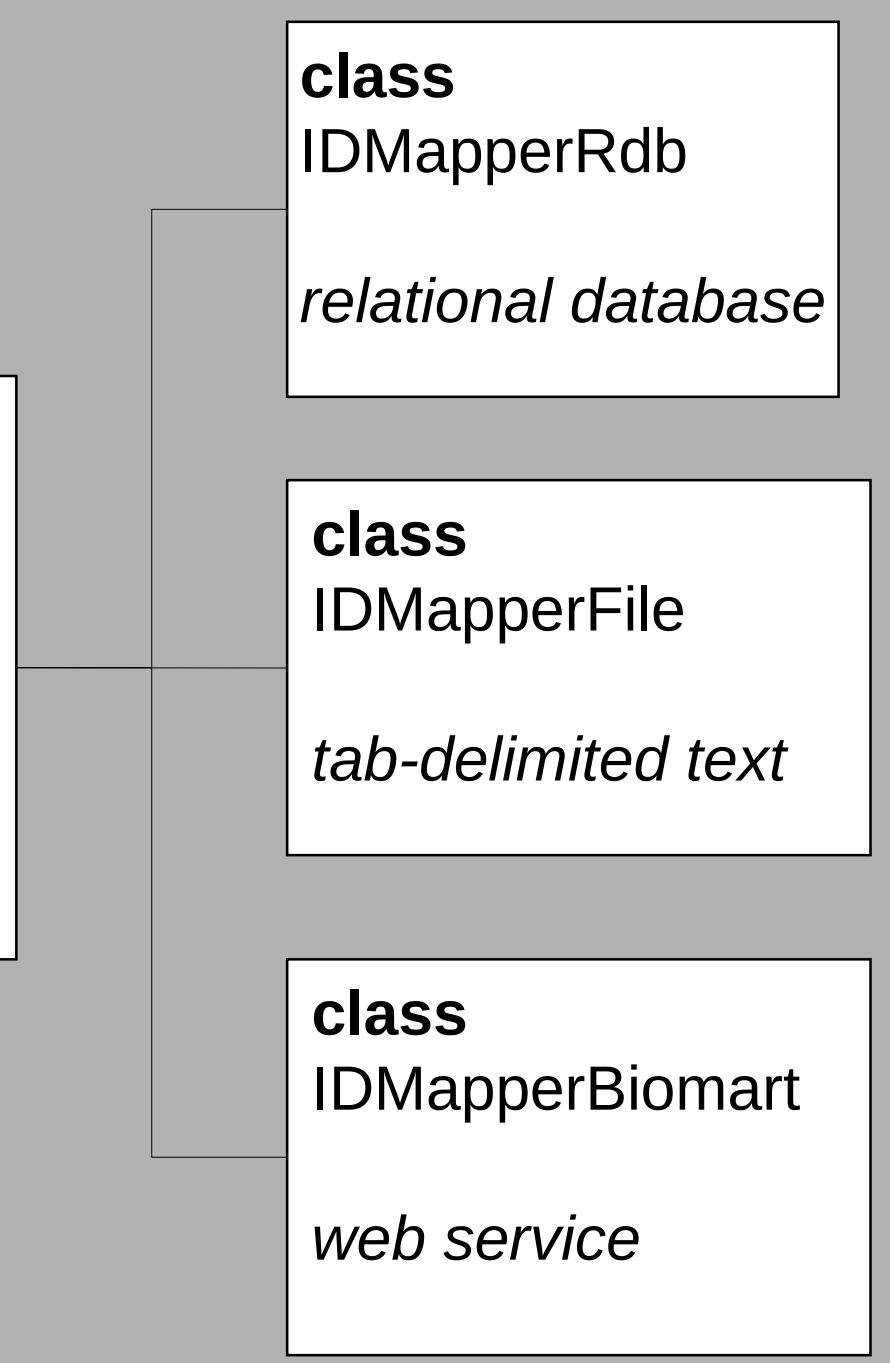

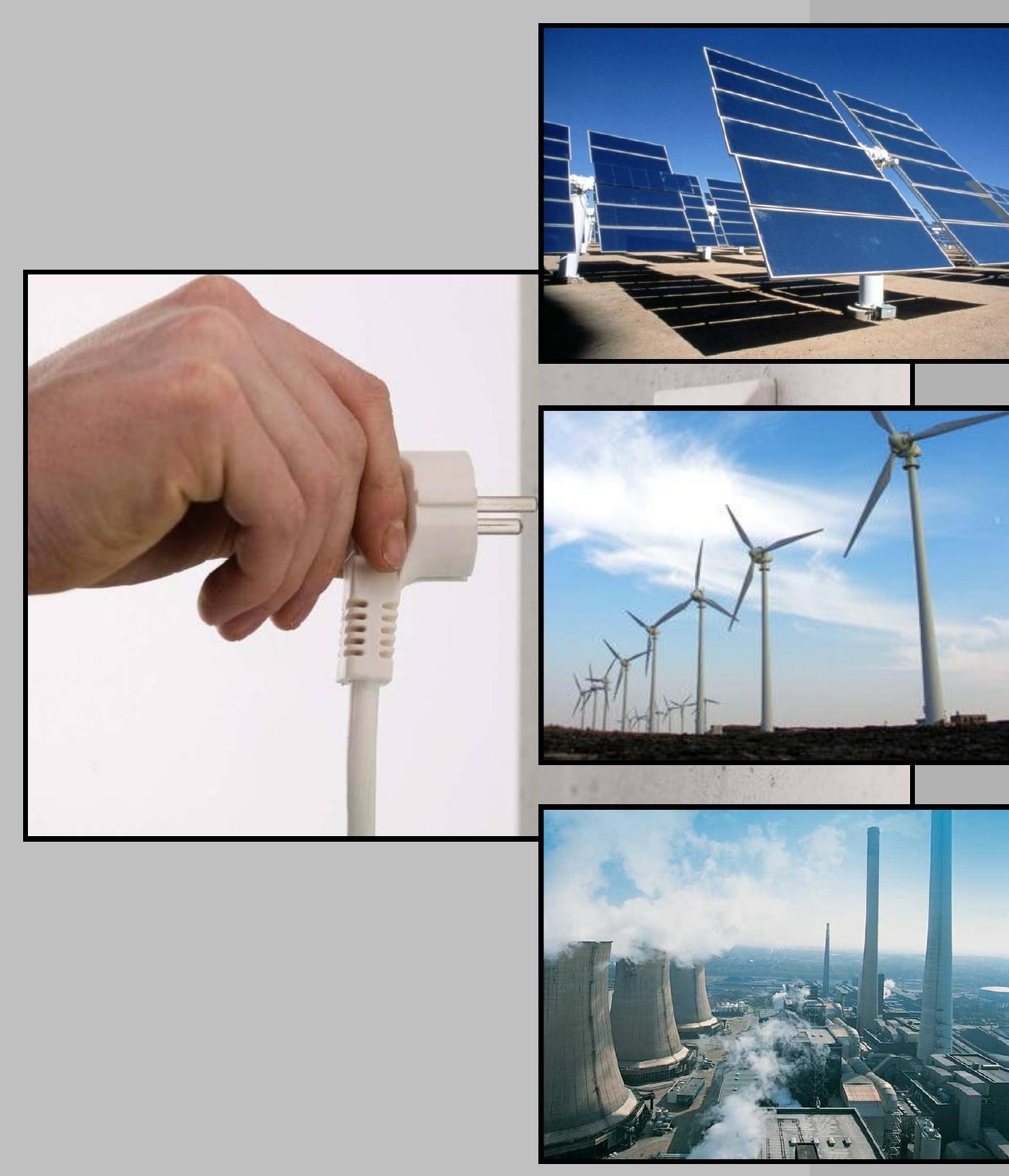




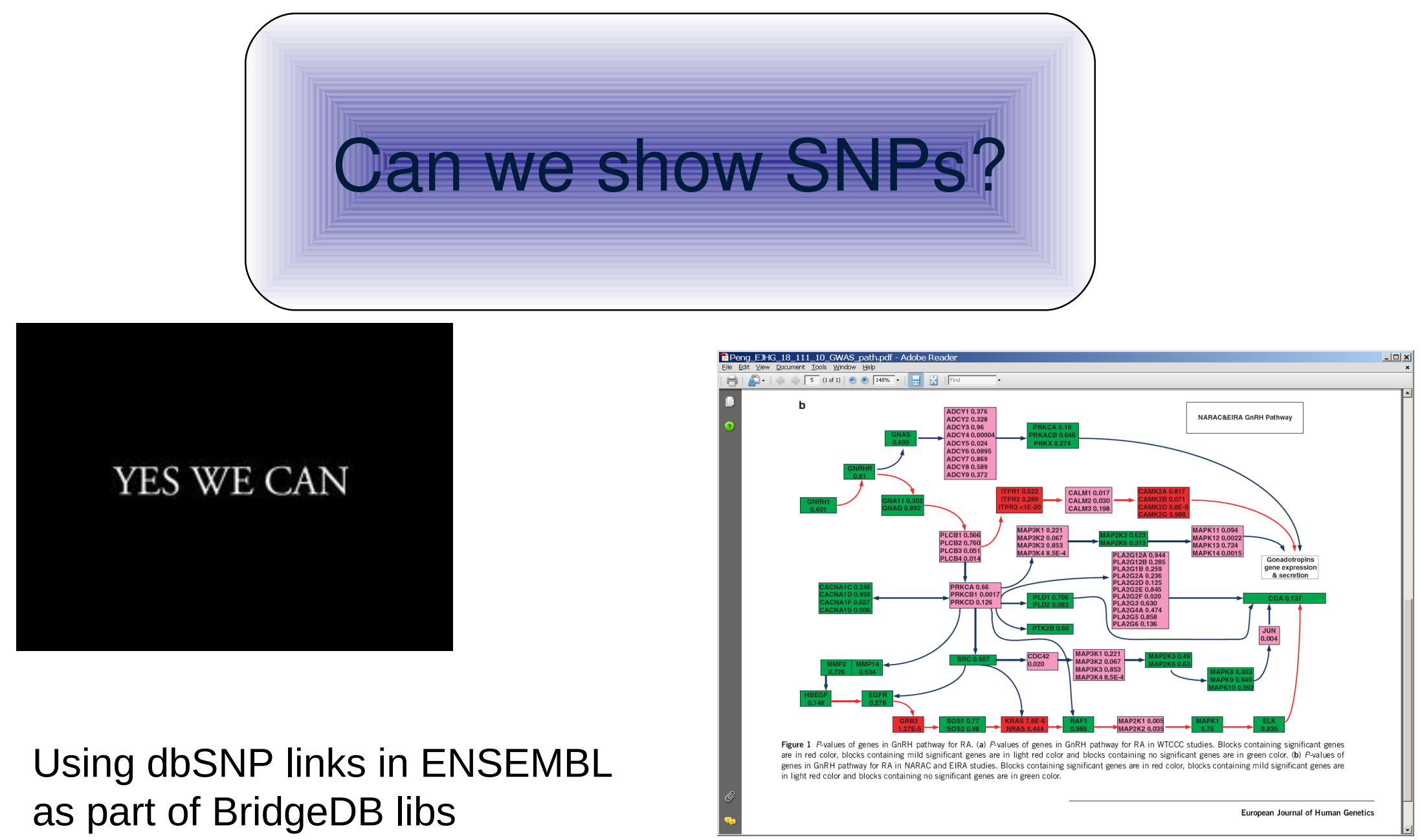




\section{Dastricht University in Leannming!}

\section{But it will look like this....}

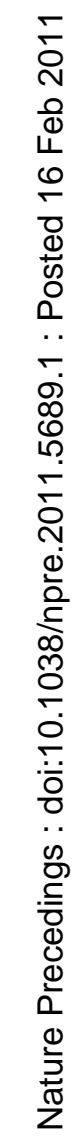

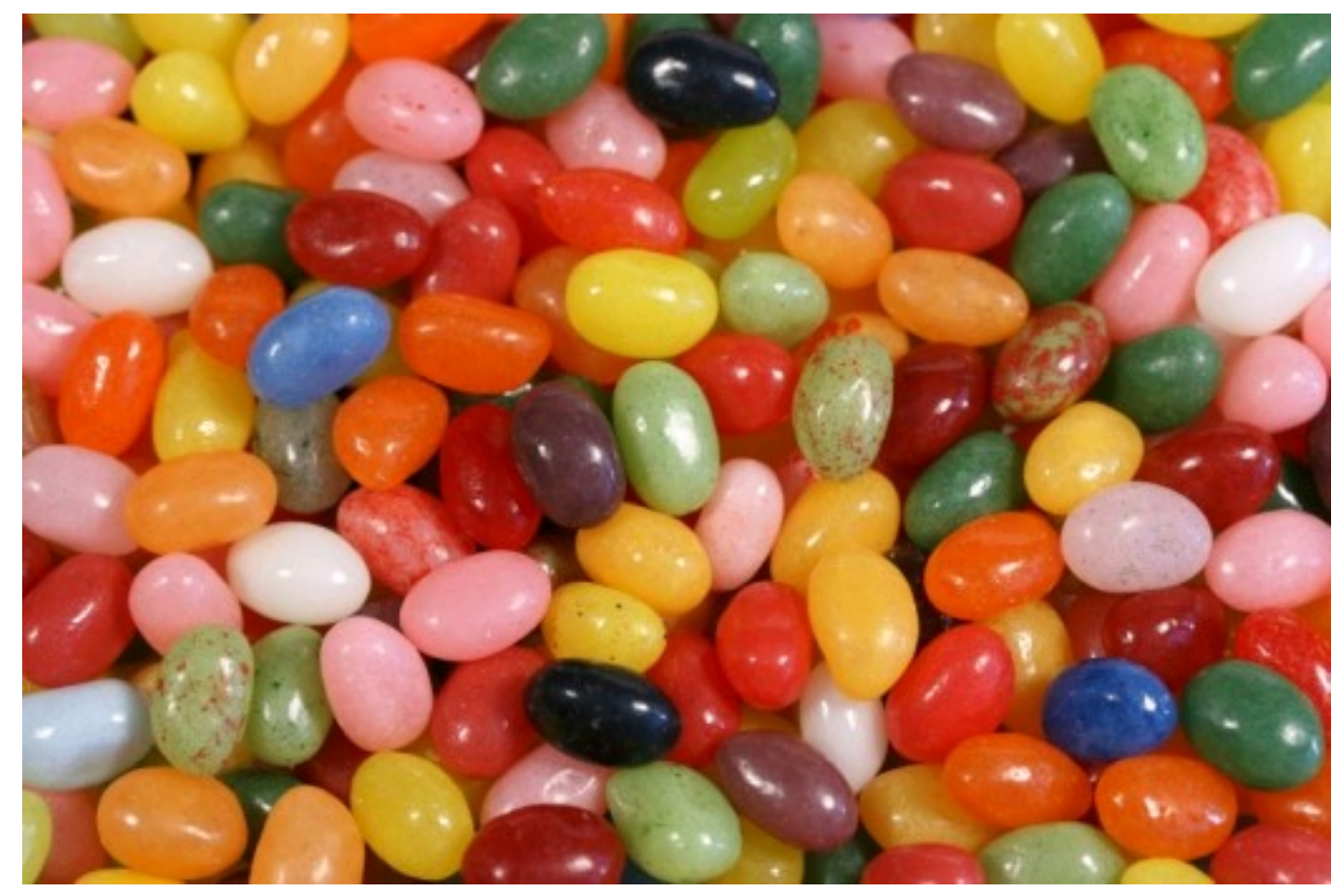




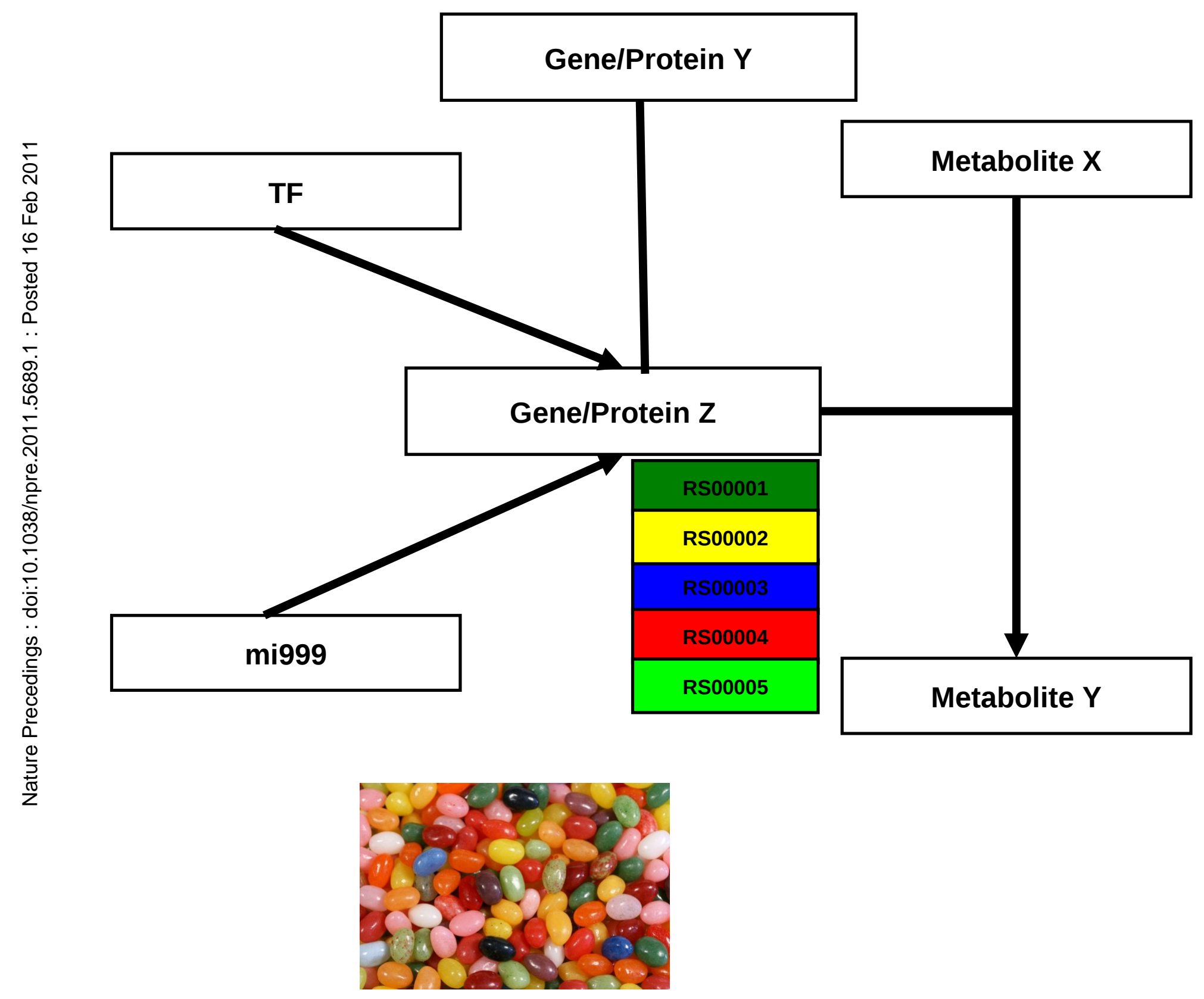


